\title{
Supporting teachers who introduce curricular innovations into their classrooms: A problem-solving perspective
}

\author{
Edit Yerushalmi and Bat-Sheva Eylon \\ Weizmann Institute of Science, Rehovot, Israel, 76100 \\ (Received 19 February 2012; published 13 June 2013)
}

\begin{abstract}
When classroom teachers introduce curricular innovations that conflict with their former deeply rooted practices, the teachers themselves experience a process of change. One professional development framework intended to support this change is the customization workshop, in which teachers cooperatively customize innovations to their own classroom contexts, reflect on the strengths and weaknesses of classroom implementation, and refine their innovations. Two goals sometimes conflict in such workshops: developing teachers' skills as reflective practitioners (process) and maintaining crucial characteristics of the original innovations (product). This paper explores how to meet both challenges using the insights from a perspective that provides a striking parallel: developing expertlike problem-solving skills (process) as well as conceptual understanding (product) in the physics classroom. We apply this perspective by (a) characterizing an expertlike approach to pedagogical problem solving in the context of customization workshops, (b) determining the nature of pedagogical problems best suited for developing such an expertlike approach, (c) suggesting how to design customization workshops that support teachers to develop an expertlike approach to pedagogical problem solving. In particular, we hypothesize that applying cognitive apprenticeship in customization workshops in a manner similar to its application in the teaching of expertlike problem solving in the physics classroom should effectively help teachers approach the pedagogical problem of customization in an expertlike manner. We support our hypothesis with an empirical study of three year-long cooperative customization workshops for physics teachers that differed in terms of mentoring approach. We examined the questions (a) under which mentoring approaches did teachers perform an expertlike pedagogical problem-solving process and (b) which practices and perceptions emerged through execution of this process?
\end{abstract}

DOI: 10.1103/PhysRevSTPER.9.010121

PACS numbers: 01.40.J-, 01.40.gb

\section{INTRODUCTION}

This paper takes a problem-solving perspective to examine an especially challenging task commonly confronting instructors: introducing curricular reforms into their classrooms whose underlying approach to learning and teaching differs significantly from their former practices. The research-based curricula developed in the past two decades and designed, for example, to advance students' expertlike problem solving in physics, their scientific practices, or their conceptual understanding through peer discussion and guided inquiry [1-17] are good examples. These curricula commonly require instructors to leave behind their deeply rooted self-perceptions as knowledge providers and accept the role of coach $[18,19]$.

Despite the wealth of research findings showing the benefits of such innovations [20,21], and the availability of a variety of instructional strategies and materials, these instructional innovations have only been sparsely and inadequately implemented. For example, it was recently

Published by the American Physical Society under the terms of the Creative Commons Attribution 3.0 License. Further distribution of this work must maintain attribution to the author(s) and the published article's title, journal citation, and DOI. reported that only $10 \%$ of high school physics teachers said they had been impacted by physics education research [22]. In a survey about the use of research-based instructional strategies by physics faculty [23], it was found that most of the participating faculty were familiar with one or more instructional innovations. However, only about 50\% of the faculty members attempted to use them, and the innovations were rarely used as intended by the developers.

Experienced teachers who have already established a functioning and effective method of instruction in their classroom often hold the view that there is no need to change their approach to instruction to comply with the recommended reform. They are suspicious of university researchers or teacher educators who do not share their constraints in the field. Likewise, they are wary of research results demonstrating the effectiveness of new curricula in achieving learning goals [24]. Nevertheless, there is a drive for change $[25,26]$ that stems from the burnout that can motivate teachers to seek renewal and the unease some teachers feel with regard to learning goals they know they have not achieved.

Research has shown that even teachers who are convinced of the need to change traditional practices and views are immersed in a culture that reflects their former practices [27]. Actualizing any change in practice requires 
reestablishing classroom routines, sometime at the cost of existing priorities. For example, the commitment to "cover the material" might conflict with the commitment to "inquiry learning" [18,19,28]. In addition, teachers have to tailor instructional materials, no matter how carefully developed, to match the constraints of their specific classroom situation. Teachers' and students' earlier preconceptions may disrupt this implementation and lead to unwanted modifications in the innovations. These changes sometimes result in a loss of key features of the innovation, and the targeted benefits are not achieved [23,29-31]. Thus, a major obstacle to the implementation of new instructional approaches that conflict with deeply rooted traditional practices is that it requires the teachers themselves to undergo a process of change.

It follows that curriculum developers' efforts to disseminate their products must come to terms with the needs of experienced teachers in the field and support a process of change [24]. Professional development programs that integrate research-based curricular innovations should do so in a manner that revitalizes teachers and helps achieve the learning goals they set for their students. Teacher educators [32-34] have recommended supporting the process of change by establishing a process of "reflection on practice" [35-40]; they expect this type of professional development approach to give teachers the opportunity to cooperatively clarify learning goals, customize innovations to their own classroom contexts, reflect on implementation, and refine instruction and materials. We refer to such professional development programs as customization workshops.

Two at times conflicting and hard-to-achieve goals are intrinsic to customization workshops: developing teachers' skills as reflective practitioners who renew their practice and accomplish goals which they set for themselves (focus on process) and directing change in teachers' perceptions in order to maintain the crucial characteristics of the original innovations during their customization (focus on product). This conundrum has prompted teacher educators to redefine what should be considered as implementation of an intended curriculum in a way that is "faithful" to its developers' intentions. For example, there are teacher educators [41] who claim that a "faithful implementation" does not necessarily involve carrying out every component of the intended curriculum. Instead, they suggest that curriculum implementations that are consistent with the theoretical foundations of the intended curriculum can be considered a "faithful implementation."

In this paper we will explore how to design customization workshops to achieve the above-mentioned goals. To this end, we will use the perspective of teaching scientific problem-solving skills, especially in the physics classroom [42-44]. We chose this perspective because of their striking parallels: the teaching of scientific problem solving confronts challenges that are similar to those of teaching pedagogical problem solving, namely, developing expertlike problem-solving skills (process) as well as conceptual understanding (product). Nevertheless, drawing an analogy between physics problem solving and the pedagogical problem solving that takes place in a customization workshop raises several concerns. One might claim that the knowledge needed for physics problem solving differs significantly from that required for pedagogical problem solving. The models used in physics can be reduced to a few variables and provide certainty in prediction. They are defined explicitly as formal relationships that need to be interpreted unambiguously in any particular instance. In pedagogical problem solving, the models directing teachers' understanding of classroom events involve multiple variables, they are not represented as explicit formal relationships, often there is no uniquely correct interpretation, and one cannot predict outcomes with absolute certainty. Moreover, models play a role in directing conscious scientific decisions, while teachers' decision making is often implicit.

But perhaps there is less of an apparent dichotomy between the two types of problem solving. When interpreting pedagogical problem situations, teachers' beliefs serve a function similar to that of concepts and principles in interpreting physics problems. These beliefs define what is considered noteworthy in the classroom [45] and shape how teachers interpret events and make decisions [46,47]. In the case of designing curricular innovations that are committed to a certain instructional paradigm, explicit models guide pedagogical problem solving in a manner similar to scientific problem solving. Moreover, one could argue that when scientists confront real-world problems, the situation is less clearly defined than in simplified exercises, and it is harder to identify a single "correct" answer.

In fact, problem solving appears in the educational research literature as a perspective for discussing teachers' learning and expertise. Teachers' learning from everyday experience is described [48] as a process of identifying problems that classrooms present and solving these problems through deliberate reflection, in action and on action [36]. An expertise scale has been suggested $[49,50]$ that uses teachers' approaches to pedagogical problem solving as one of the criteria for differentiating between an expert and a novice.

We use the problem-solving perspective somewhat differently from the above. We focus on the special context of professional development programs that take a problembased approach in which the participants share a common pedagogical problem and collaborate in constructing a solution [51]. In particular, we focus on customization workshops in which teachers are expected to refine existing solutions to a pedagogical problem. The customization process involves the tailoring of research-based instructional strategies to fit the teachers' own classrooms, 
followed by implementation, reflection, and redesign of the learning materials and instructional strategies. An effective customization process involves a systematic, iterative, and cumulative problem-solving process where teachers identify goals and examine their achievements via various courses of action. In this paper, when we refer to an expertlike pedagogical problem-solving process we mean the customization process mentioned above.

The literature on teaching problem solving guides us in the following aspects of designing customization workshops.

(1) Choice of tasks. Which pedagogical problems are suitable as subjects of customization workshops aimed at developing expertise in pedagogical problem solving?

(2) The nature of expertise. What characterizes expert pedagogical problem solving in the context of customization workshops?

(3) Teaching problem solving. How can we support teachers in developing expertise in pedagogical problem solving?

In the following sections, we first describe central notions from the literature on the teaching and learning of physics problem solving. We will recap the insights gained from applying the problem-solving perspective to pedagogical problem solving in customization workshops. Second, we describe an empirical study that we conducted to investigate the third issue mentioned above. This study focused on three year-long cooperative customization workshops for physics teachers that differed in terms of the mentoring approach provided. The ostensible goal of the workshops was to support the participating teachers in promoting the expertlike problem-solving behavior ${ }^{1}$ of their students. In this context we studied the following questions: under what mentoring approach do teachers enact an expertlike pedagogical problem-solving process? Which practices and perceptions do teachers develop through such a process? In particular, we examined a hypothesis derived from the physics problemsolving perspective described below that mentoring aligned with cognitive apprenticeship in customization workshops helps teachers approach pedagogical problem solving in an expertlike manner. We conclude by discussing recommended design guidelines that support cooperative pedagogical problem solving in customization workshops aimed at introducing innovative instruction into the classroom.

\section{FROM PHYSICS PROBLEM SOLVING TO PEDAGOGICAL PROBLEM SOLVING}

Research on expert and novice differences in problem solving and instructional strategies to support the

\footnotetext{
${ }^{1}$ We emphasize that this paper discusses two distinct problemsolving processes: that of the teachers who participated in the workshops and focused on pedagogical problems, and the reflective process of solving physics problems the teachers try to develop in their students.
}

development of problem-solving skills has a long history in the physics education research community. In this paper we adhere to central notions in this literature.

\section{A. Choice of tasks-Which pedagogical problems are suitable as subjects of customization workshops aimed at developing expertise in pedagogical problem solving?}

A problem is defined [52] as a situation in which one does not know how to reach the goal. The problem-solving process is described as a search through the space of possible solution paths. In the problem-solving process, the solver encounters decision junctions where she or he is free to choose among several possible actions that are more or less clearly defined, and more or less legitimate [44]. A problem is distinguished from an exercise by the solver's degree of freedom to make choices at each decision junction in the solution process. In an exercise-solving process, the solver knows how to reach the goal and she or he carries out a preset procedure almost automatically. Thus, whether a problem functions as an exercise depends on the knowledge of the solver.

In the physics classroom, exercises are presented in a way that makes it easy for solvers to map and retrieve the knowledge needed for their solution. For example, they are represented in a format familiar to the solver and are set up in a previously encountered context (surface structure); multipart problems are decomposed into subproblems, making explicit the intermediate variables and principles to be used, thus making it easy to recognize the knowledge needed to solve a problem. Rather than simplify the problem-solving process, some research-based curricula contain tasks that engage solvers in elaborated problemsolving processes. These problems require students to practice decision making by analyzing the problem situation, identifying the physics concepts needed to solve the problem, decomposing the problem into subproblems as needed, planning the execution of the solution, and evaluating the results of the solution. Thus, they spur the solver to reflect and refine his or her understanding of the concepts and principles applied. Examples of such problems are contextrich problems [3], experiment problems [53], real-world problems [54], and thinking problems [55]. These problems are presented in a real-world context; they typically require more than one step to solve, and often they are not accompanied by diagrams. Finally, they may contain more or less information than is needed to solve them.

When considering teachers' everyday decision making, one can likewise differentiate between classroom situations that function either as problems or as exercises. Unfamiliar situations requiring the teacher to consider alternative solutions would then be categorized as pedagogical problems. Situations that have been encountered numerous times before would be considered pedagogical exercises that require the experienced teacher merely to 
implement well-established solutions. Research [50] points out that experienced teachers acquire a large inventory of case studies that allows them to readily identify and retrieve meaningful schemas needed to solve the pedagogical problems they face, almost without having to engage in conscious thought, thus reducing these problems to mere pedagogical "exercises." For example, an experienced physics teacher whose class is studying Newton's third law would readily identify misconceptions expressed by students and would have a ready arsenal of demonstrations to confront the students with their misconceptions. The novice teacher knows very few preset procedures to achieve his or her goals; on top of this, she or he is overwhelmed by the numerous details of running a classroom [49] - thus, almost everything is conceived as a problem and not as an exercise.

Now let us consider the pedagogical problem explored within a customization workshop dealing with a curricular innovation. Again, whether customization of some particular instructional innovation is a problem or an exercise depends on the resources possessed by the teachers. If the innovation preserves most of the teachers' customary instructional structures, then the teachers are facing an exercise. For example, teachers can be considered as facing an exercise when adopting a new technology that they can master before entering class, without changing learning goals or traditional responsibilities; the teachers can be taught the procedure and can implement it with minor adjustments.

It is when the innovation challenges basic views and practices that the teachers who adopt it face a real problem: the profound changes that are needed can be achieved only through the very processes of applying the new classroom practice, reflection. and elaboration. We will term these problems fundamental pedagogical problems; they are the parallel, in the pedagogical world, to the aforementioned tasks that engage solvers in elaborated problem-solving processes, such as "context-rich problems." Unfortunately, developers of instructional innovations that require a fundamental change in teachers' views and practices sometimes mistakenly expect the implementation of an innovation to be a mere exercise [24].

Research claims that to be useful in teacher renewal, a challenge should prompt teachers to confront basic questions regarding learning and teaching, and encourage them to wrestle with conflicts between innovative instruction and their former practices [26,56]. Findings suggest that experienced teachers are open to such uncertainties. For example, a study on a group of experienced teachers participating in a program aimed to develop them as leaders of regional science teacher centers [25] portrays their professional development as a continuous cyclic process that has four stages: (1) challenge, (2) self-fulfillment, (3) new routine, (4) junction. The teachers attempted to renew their practice by taking on new challenges, rather than declining into a routine period of repetition.
Fundamental pedagogical problems that are suited for customization workshops present experienced teachers with challenges that provide an opportunity for teachers' renewal. These teachers have reached a stage where regular classroom practice no longer challenges them and when much of their decision making has become automatic and no longer requires their time or cognitive resources. The challenges offered by a customization workshop dealing with fundamental pedagogical problems can assist teachers in considering overlooked facets in class events and in exploring less certain and expected action plans [57].

\section{B. The nature of expertise-What characterizes an expert pedagogical problem in customization workshops?}

In physics and math, experts (e.g., experienced physics instructors) and successful novices have been found to approach problem solving in a different manner than unsuccessful novices. Experts devote considerable time to first representing a problem situation qualitatively and making simplifying assumptions [58,59] that might help solve the problem, and then revise their representation if necessary [60], moving between available representations more quickly [61].

The knowledge base of experts is characterized by a larger vocabulary of knowledge chunks and it is organized at a deeper principle-based level than that of novices [62]. Experts retrieve effective representations for use in analyzing a problem situation that derives from their knowledge base. In contrast, the novice typically matches chunks based on surface features, using earlier problems as templates for matching new problems [63]. Expert problem solvers are also characterized by a strategic approach to solving problems rather than the haphazard trial-and-error approach focused on plugging numbers into formulas that characterizes novices [42,64-68]. Experts group together solution steps into useful subproblems while novices tend to perceive each solution step separately [63]. Researchers have described novices' poor access to relevant knowledge and procedures in terms of "epistemic games" [69]—a locally coherent set of behavioral rules for achieving particular goals that portray certain problem-solving behaviors. For example, in the epistemic game "recursive plug-and-chug," resources such as attempting to relate physical meaning to some quantity are not activated.

The process of solving problems allows solvers to refine their understanding of pertinent concepts and principles [70], in particular, if they engage in deliberate [5,66,71] reflection on their interpretation of the concepts and principles involved in the process of solving a problem. However, it has been shown that even students who had solved more than 1000 traditional problems were unable to overcome related conceptual difficulties [72], suggesting that many novices do not make use of problem solving as a learning opportunity. Indeed, successful problem solvers 
were found to better assess their state of understanding when studying worked examples and to generate more self-explanations than their less successful peers [63]. Students' beliefs with respect to the nature of physics knowledge and learning are consistent with these results.

The same issues arise in pedagogical problem solving: namely, whom we consider an "expert" and which problems promote expert approach.

Using the characterization of expert problem solvers as a model, we expect the knowledge base of expert pedagogical problem solvers to be organized hierarchically. We expect that when they are engaged in the customization of curricular innovations these teachers would be committed to a certain paradigm and to ensuring that the critical instructional features stemming from this paradigm will be present. We would also expect the expert pedagogical problem solver to employ a systematic, iterative, and cumulative problem-solving process; the process should involve data collection tools (observations, interviews, questionnaires, etc.) and data analysis procedures to yield well-grounded conclusions on diverse aspects of a given reform. These aspects might include students' preconceptions and their actual performance during the introduction of the innovation.

Who might be considered an expert pedagogical problem solver?

One might assume that the natural example of an expert pedagogical problem solver is an experienced teacher who has accumulated expertise in teaching. If this is an appropriate choice, these teachers' learning can be portrayed as a systematic, iterative, and cumulative reflective process accompanying classroom practice. The literature proposes that teachers change their perceptions through an iterative reasoning process [73].

Frequently however, teachers' adaptations of curricular innovations are guided by their former views and by the pushes and pulls of diverse systemic pressures [74,75], some of which are aligned with the innovation and some in conflict with it, rather than by explicit models or even by an explicit set of priorities. The principles around which their rich knowledge is organized may differ significantly from those underlying the innovations they are attempting to adapt. As a result, even teachers who have consciously adopted new views and goals may still, by default, unconsciously interpret and respond to the rich class information available based on their former views $[28,29,76]$. Teachers generally perform more of their reflections in action or soon after events have occurred, and less frequently carry out conscious, explicit after-the-fact introspection [48]. As a result, while occasionally they are aware of contradictions between various intentions, they might not analyze how these play out in the classroom and how to best handle them to preserve the critical features of the curricular innovation. The very experience that otherwise enables their fluid performance can get in the way of their attempt to change their instruction, locking them into existing views and practices. Thus, the knowledge base underlying teachers' efforts in such endeavors resembles that of novice problem solvers.

Alternatively, one can consider curriculum developers to play the role of expert pedagogical problem solvers, in particular, if they take a design study [77] approach by testing interventions under development concurrently in the classroom. A design study approach affords sensitivity to the dynamic classroom context, one that requires an immediate response to students' difficulties and systemic constraints. Design studies accompanying the development of curricular innovations involve a systematic, iterative, and cumulative problem-solving process. They research, in specific settings, whether implemented curricular innovations are committed to some paradigm and adjust their design to be consistent with the curricular goals associated with that paradigm. Accordingly, in this paper we will view curriculum developers engaged in a design study as expert pedagogical problem solvers. We will cast teachers, even experienced ones, in the role of novice pedagogical problem solvers when facing fundamental pedagogical problems (i.e., pedagogical problems such as the customization of instructional innovations to their classrooms).

\section{Teaching problem solving}

As mentioned earlier, most students need support in order to develop expertlike problem-solving behavior. Instructors rarely explicitly support the learning process that should take place while students solve problems, or develop in students an expertlike approach to problem solving $[78,79]$. The typical approach is to assign problems to solve and provide help when students cannot get by on their own and request the teacher to help them. We will refer to an approach that involves students in problem solving without explicit guidance as a means of developing their problem-solving skills as the minimal guidance approach. Another common approach to teaching problem solving is to involve students in semiexercise solving. We will refer to this approach as the spoon-fed approach. In this approach, textbook problems are represented schematically and are decomposed into parts. Thus, textbooks often transform problems into semiexercises, effectively bypassing the essential skills of choosing representations and planning strategy in which novices are weakest $[42,43]$. But because of this very avoidance, solving many exercises will not transform a novice into an expert problem solver. Moreover, teachers frequently model correct procedures to solve a problem without demonstrating that the correct procedure was arrived at through exploring alternative solution paths. A possible outcome is that students will draw the conclusion that one should have a ready method for the solution of a given problem and the method should produce an answer to the problem in just a few minutes [80]. Thus, they might perceive problems as mere exercises. 
While the instructional strategies described above fail to develop an expertlike problem-solving approach, there are research-based practices that show that such an approach can be taught and learned. For example, the cognitive apprenticeship [81] approach underlies many [82] pedagogical techniques $[1-4,6]$ that have been shown to promote expertlike problem solving [4,83]. In this approach, the authentic work environment of the expert, that requires an elaborated problem-solving process, is mimicked by presenting problems that involve a real-world context [3,53-55]. The tacit problem-solving strategies of experts are externalized in a prescribed problem-solving framework $[2,5,68,84]$ that is modeled in the examples of problem solutions that the instructors present to students. Later on, students are required to use the strategy in their own solutions. Cognitive apprenticeship involves providing initial scaffolding and later fading [3]. One way to provide scaffolding is by structuring group work to provide opportunities for peer and/or self-evaluation through role allocation based on formats found in the literature to be effective [85].

Given our inference that teachers are novice pedagogical problem solvers when faced with customizing curricular innovations, it follows that teachers' expertise in this domain needs to be developed. How can we support teachers in developing expertise in pedagogical problem solving? Again we will search for guidance in the literature that discusses the development of expertise in physics problem solving.

Extending the analogy from the above, we inferred that in addition to choosing an appropriate fundamental pedagogical problem for customization workshops, the choice of mentoring approach in these workshops should have a significant impact on the chances for the participating teachers to develop expertise in pedagogical problem solving. Three distinct mentoring approaches have been discussed: the minimal guidance approach, the maximal guidance (spoon-fed) approach, and the cognitive apprenticeship approach. Research has shown that the first two have not been successful in developing students' problemsolving expertise. Considering the minimal guidance approach, we infer that it may not be sufficient to simply assemble teachers in a customization workshop and provide them with help when they encounter difficulties in coping with the challenge on their own. Even if they are eager to adopt an innovation, such an approach will not yield an expertlike approach to pedagogical problem solving. As for the spoon-fed approach, we infer that subdividing the task and overguidance of the teachers in each step of the customization process will not lead to expertise in pedagogical problem solving.

Inspired by the application of cognitive apprenticeship to developing expertlike problem solving in the physics classroom, we suggest that it is a mentoring approach suitable for customization workshops. Such mentoring would involve workshop participants in exploring solutions to fundamental pedagogical problems. Scaffolding would be provided by structuring teachers' work, requiring them to follow a prescribed expertlike pedagogical problem-solving strategy, and structuring group discussion through role allocation to provide opportunities for peer and/or self-explanation and evaluation.

The goal of the study described in the next section was to investigate empirically the above-mentioned inferences concerning the three mentoring approaches and their potential to develop the pedagogical problem-solving expertise of experienced teachers.

\section{THE STUDY}

As mentioned above, the goal of this study was to empirically identify mentoring approaches that foster expertlike pedagogical problem solving and, in particular, to examine the hypothesis that mentoring aligned with cognitive apprenticeship in customization workshops helps teachers approach pedagogical problem solving in an expertlike manner. To that end, we studied three workshops in which teachers customized innovations requiring changes in deeply rooted views and practices. As discussed above, such a customization task presents teachers with a fundamental pedagogical problem and provides a context in which they can develop expertise in pedagogical problem solving.

The mentoring in the three workshops differed in terms of the intended distribution of roles between the workshop leader and the participants. One of the workshops was planned to provide minimal guidance (the minimal guidance approach), another maximal guidance and structuring (the spoon-fed approach), and the third workshop was modeled after the cognitive apprenticeship approach.

As described below in detail, the three workshops involved extensive interactions between the mentor and the teachers, who responded to the ongoing construction of knowledge by the teachers. Therefore, before studying the processes and outcomes of the different approaches, it is necessary to examine how each of the approaches was enacted and to what extent it indeed implemented the intended approach. We will then report on the study of two research questions.

(1) To what extent did each of the mentoring approaches lead to the development of an expertlike pedagogical problem-solving process?

(2) What were the practices and perceptions developed by the participating teachers in workshops where an expertlike pedagogical problem-solving process took place?

\section{A. Method}

\section{The sample}

Each of the workshops involved a small group (five to eight participants) of teachers preparing their students to 
take the national physics matriculation exam. Except for one teacher who had 8 years of experience, all the other teachers had over 20 years of experience. Their class sizes ranged from 15 to 35 students. The schools represent a variety of achievement levels, as measured by the average matriculation exam grades of these schools.

\section{The workshops}

As mentioned earlier, three versions of a year-long workshop for high school physics teachers took place. All of the workshops aimed to explore the fundamental pedagogical problem of promoting students' expertlike problem-solving behaviors. All versions involved teachers in cooperative reflection on their practice while customizing curricular innovations into their classrooms. The workshops consisted of five components. The content of components (a) and (b) (presentation of research literature and constructivist activities) was similar across the three workshops, although their form differed. In workshop A (minimal guidance) these components were spread over the first third of the workshop during the school year, while in workshops $\mathrm{B}$ and $\mathrm{C}$ they were concentrated in the summer workshops. The other workshop components [(c)-(e)] were all part of the collaborative customization of the innovations that were introduced in components (a) and (b) to the participating teachers' classrooms: the development of modified versions of the innovations, implementation, and reflection. A short description of these components follows:

Component (a): Presentation of the research literature.The participants were acquainted with the findings of laboratory and classroom research regarding physics problem solving, its learning and teaching, and with resulting curricular innovations that attempt to achieve expertlike problem-solving behaviors in introductory physics students $[1-5,9,10,62,63,86-89]$. They focused mostly on innovations that take a cognitive apprenticeship approach and on innovations that employ alternative assessment methods.

Component (b): Constructivist activities.-These were designed to expose existing beliefs of the participants about teaching and learning problem solving and to raise conflicts with the research literature. Activities lasted 1-2 hours and were performed individually or in groups of two or three members. A sample constructivist activity was "sorting problems." The participants were asked to judge concrete instructional artifacts comparable to those they encounter in their teaching environments. They were given five possible ways to state the same problem; what differed was the solution process they required of the student (e.g., a problem that provides a diagram. and is broken down into explicit subproblems, does not require students to draw a sketch or identify subproblems, whereas a problem that lacks these elements does). The teacher participants were also given worksheets that asked them to identify categories that they found useful in differentiating between the problems and to sort the problems into these categories. The artifacts used resemble those described in a study investigating instructors' reasons for choosing problem features in a calculus-based introductory physics course [19]. The categorization was discussed, allowing the teachers to reconstruct their experience as problem solvers and as teachers, to reveal their beliefs regarding the process of solving a problem and their instructional considerations in designing problems for their students, and to reflect on and examine their beliefs, goals, and practices while constructing a mutual professional language. An example of the type of conflict such an activity can expose is between the prevailing structure of problems like those on the matriculation exam and the recognition that such a structure does not encourage students to develop important aspects of problem solving. In another activity the workshop participants were provided with examples of prescribed problemsolving frameworks suggested in the literature as means to externalize and model to students the tacit problem-solving strategies of experts $[1,3,5,86]$. They were asked to use these frameworks to solve specific problems on their own and reflect on their experience while comparing the various frameworks they tried out.

Component (c): Development of instruction and materials.-The participants were asked to form pairs or triads interested in implementing the same instructional innovation. Each team was asked to define procedures appropriate to their classroom contexts and to write the accompanying materials. This component took place during face-to-face workshop meetings as well as between meetings via Email and phone calls.

Component $(d)$ : Implementation.-The teachers were asked to implement the instruction and materials they had developed and to report back at a subsequent workshop meeting.

Component (e): Reflection.-After teachers experimented with the modified innovations in their classrooms, they reflected cooperatively on the experience in the meeting, evaluated the innovations, and discussed how to refine them.

The form of the last three components differed among the workshops.

Workshop A-Minimal guidance.-Workshop A was carried out during one school year and included 18 meetings, $\sim 2.8$ hours per meeting. In addition, participants' class time involved the implementation of instructional strategies discussed in the workshop ( $\sim 4$ hours). In this workshop the approach was to first present teachers with the research literature, then to ask teachers to choose innovations they would like to try out in class and develop, individually or in pairs. The teachers were then asked to elaborate the instructional procedures and materials appropriate to their classrooms, implement the instruction and materials, suggest methods by which to evaluate the instructional innovations, and carry out this evaluation. While the teachers were expected to initiate and carry 
out the directions for the cooperative work, there were no explicit rules or designated time slots guiding them on how to do so. However, the workshop leader intervened when the teachers did not make progress on their own.

Workshop B-Maximal guidance.-Workshop B had two parts. The first part consisted of a 2-day summer workshop to enable teachers to make a decision of whether to participate and commit themselves to a yearly workshop. The second part took place during one school year and included 14 meetings, $\sim 3$ hours per meeting. In addition, participants' class time involved the implementation of instructional strategies discussed in the workshop five times ( $\sim 10$ hours). In this workshop the approach from the beginning was to leave the decision regarding which innovations would be developed in the hands of the workshop leader. Workshop meetings were dedicated to the development by the teachers of materials to accompany these innovations. The workshop leader contributed resources from the literature for teachers to integrate into the materials they developed. Teachers were asked to implement in their classrooms the instruction and materials that they had developed and, in subsequent workshop meetings, to give feedback and discuss their concerns regarding the implementation. At that point again, the workshop leader decided upon the direction to explore in the next development and implementation modules, and so forth. To summarize, the teachers were expected to execute what the workshop leader planned.

Workshop C-The cognitive apprenticeship mentoring approach.-Workshop $\mathrm{C}$ had two parts. The first part consisted of a 2.5-day summer workshop to enable teachers to make a decision of whether to participate and commit themselves to the workshop. The second part took place over two school years. The first year included 14 meetings of $\sim 3$ hours per meeting, and 4 meetings of 6 hours each. The second year included 14 meetings of 3 hours each. For the purpose of this study, only the first part of the workshop, similar in length to workshops A and B, was used for analysis. In this period, in addition to workshop time, the participants' class time involved the implementation of instructional strategies discussed in the workshop 6 times ( $\sim 12$ hours). The results of the rest of the workshop were used for in-depth analysis of the cognitive apprenticeship mentoring approach. In this workshop the decision regarding which innovations would be developed was in the hands of the participants, but the cooperative work was managed through a repetitive cycle of activities structured by clearly defined schedule targets and participant responsibilities. We termed this structure the "flag person framework," because, in each cycle, while all participants were to try out innovative instruction in their classroom, one participant at a time took turns in the role of "presenter"; as the "flag person," she or he had to document and report on his or her classroom experience.

The presenters were asked to include in their documentation a description of the goals they felt were needed for the classroom activity, the tools used (e.g., instructional sequence and related materials distributed to students in the classroom), and results (e.g., student work and other feedback on classroom activities). The peers' role was to give feedback on the documentation. Then the presenter was required to formulate questions about his or her instructional concerns regarding this experience for a discussion in which all teachers were asked to participate. The workshop leader provided a summary of the discussion including concerns and possible instructional directions for future work. The teachers were asked to choose from these possible instructional directions, and meetings might then be devoted to developing related materials. The role of the workshop leader was to remind participants to fulfill their roles on schedule, probe for details by asking teachers to expand on issues they had raised, and request that they justify their actions by connecting details of the instructional design to the workshop goals.

The flag person framework was implemented in both face-to-face meetings and via a computerized network setting in forums and conferences that were password protected, giving only the participants access. Most cycles were actually implemented online. Each online cycle extended over 2 weeks, with the following schedule:

- Wednesday: Presenter uploads documentation of instructional innovation she or he carried out in the classroom to the workshop forum.

- The following Wednesday: Peers upload their feedback to the workshop forum.

- Thursday 6 p.m.: Presenter uploads his or her questions to the workshop forum.

- Thursday 10-11 p.m.: All participants join the e-discussion.

After several cycles: Workshop leader provides a summary of the discussions and the participants choose directions to follow.

\section{Data collection}

We documented all public interactions among the workshop participants in the context of the year-long workshops. These data captured both the collaborative solution effort and the interaction between mentor and teachers. Data were collected both in face-to-face and online workshop meetings.

The analysis took the different workshop lengths into account. In studying the execution of the pedagogical problem-solving process, we focused on the customization process, and hence we excluded from the analysis the introductory summer sessions that were added in workshops B and C. These summer sessions consisted of a presentation of the research literature [component (a)] and constructivist activities [component (b)] and did not relate directly to the customization process. Workshop A (minimal guidance) lasted about 49 hours and the customization part of workshop B (maximal guidance) lasted 
about 42 hours, a roughly similar length of time. To enable comparison between workshops, we selected and analyzed data from the first 45 hours for workshop C (cognitive apprenticeship).

We also asked the teachers to answer an initial questionnaire regarding students' approaches to problem solving and teachers' practices in this context.

The face-to-face meetings each lasted between 2 and 3 hours and were held in a science teacher education center in a university setting. A video camera located in the corner of the meeting room focused on the presenter who stood in front of the group, and an audiotape recorder was located on a table nearer the group. A transcript of the meetings was prepared from the tapes. We collected as data any documents distributed to the participants by the workshop leader or by one of the teachers.

The online meetings took place via a server running communication software that connected the participants (Worldgroup Server software by Galacticomm, Inc.). The software provided electronic mail (text and attachments), password-protected forums, and chat rooms enabling the exchange of textual and graphic information. Emails, attached files sent to the forum, and the protocols of electronic conferences were all collected.

\section{Units and categories of analysis}

As described above, the analysis proceeded in two steps. First we attempted to characterize the mentoring that was implemented, and then studied the pedagogical problemsolving process that took place in each of the workshops. For each step we chose an appropriate unit of analysis as described below.

Characterizing the implemented mentoring via "information exchanges."-We first determined the mentoring approach of each workshop. To this end, we analyzed the distribution of roles between mentor (workshop leader) and participants and defined an analysis unit dubbed "information exchange" to represent an information transfer among group members (including the mentor). This methodological approach derives from an approach to tutoring in the context of problem solving that perceives the effectiveness of tutoring as dependent upon the nature of the interaction between tutors and students [90]. Thus, the analysis examined the following questions: Are tutors and students maximally interactive, with the tutors eliciting responses from students and the students responding to tutors' elicitation? Who initiates the interaction?

Accordingly, this unit refers to the following four variables.

(1) Agent A (teacher, peers, leader)

(2) Agent B (teacher, peers, leader, class, text)

(3) The subject (learning materials, classroom activity, research topic)

(4) Representations (visuals, thoughts, text, speech)

Agent A stands for the active agents in the workshop. Agent $\mathrm{B}$ includes additional agents, class, and text to represent information exchanges such as teachers' observations in their classrooms, working on resources from the literature, etc. The transcript of the workshops was classified according to these exchange units and we characterized each exchange unit according to the following categories.

Location: 1. workshop; 2. home; 3. classroom.

Who was active? 1. workshop leader; 2. leader and teachers; 3 . teachers.

Who initiated? 1. workshop leader; 2. leader and teachers; 3. teachers.

When the teachers responded to a direct request by the workshop leader, we assigned a value of 1 (workshop leader) as the initiator, whereas when participants asked to address an issue, we attributed a value of 3 (teachers). Sometimes it was not clear who had initiated a particular information interchange, for example, during a summary discussion where decisions on future actions were made mutually. There we assigned a value of 2 (leader and teachers).

Approximate duration of information exchange: We estimated the time in multiples of 5 minutes. The time distribution of the categories sheds light on the interaction between the mentor and the teachers participating in the workshop.

For example, a teacher's presentation to his workshop peers of a class activity consisted of several "information exchanges": teacher's observation in class, account to peers, peer feedback. "Observation in class" was characterized in the following way: "The teacher represents information from the class on the subject of classroom activity from representation in the form of visuals and speech to representation in the form of thought." The workshop was represented as a series of information exchanges. This sometimes required summarization of interactions. For example, peer feedback on a teacher's account to peers might be provided by several group members, interrupted by the answer of the presenting teacher, etc. We grouped together all the peer feedback regarding a specific account into one information interchange unit.

Characterizing the processes and products of the workshop via "episodes."-In order to analyze the processes that the teachers experienced during the workshop, we defined a unit of analysis that we termed "episode." The episode unit grouped together several "information exchanges" that shared similar content (e.g., selfdiagnosis). An episode could take place as part of one workshop meeting or extend over several meetings. We formed a uniform representation for the episodes that includes its topic, the resources it utilized, the materials it produced, the meeting in which it occurred, and a brief description (see Fig. 1).

The episodes were categorized into expertlike pedagogical problem-solving steps (Table I) that should take place in a customization workshop. This categorization enabled 
Episode 6, Workshop A (minimal guidance): Self diagnosis

(Meeting 5) The workshop leader distributed sample instructional strategies from the educational research literature dealing with self-diagnosis within problem solving. She initiated a discussion on the following questions: What goals might such activities serve? Which, if any, of the teachers' students would benefit from such activities, and how would teachers expect students to perform? Teachers raised and discussed additional questions, such as whether such activities should involve a fading stage. The participants and leader agreed that the teachers would choose a specific instructional strategy dealing with self-diagnosis within problem solving, select a topic for which they would like to implement the strategy, and write related materials.

Products: A summary that included a) the instructional strategies teachers considered trying out, and b) a distinction between teacher's diagnosis, student self-diagnosis, and guided self-diagnosis

FIG. 1. Example of an episode description.

us to investigate to what extent an expert pedagogical problem-solving approach took place. These steps included:

Analysis. Discussion of possible goals, examination of the extent to which these goals were achieved in existing practice, subsequent redefinition of goals.

Planning. Proposal of possible instructional strategies for achieving the specific goals, choice of a specific course of action from among those proposed.

Implementation. Development and classroom implementation of activities and materials.

Evaluation. Examination of the extent to which goals were attained, start of a new solution cycle during which the intervention was diagnosed and refined.

The planning and implementation constitute the actual solution construction.

The information exchange analysis described above was associated with each of the episodes, thus resulting in a rich description of the processes that the teachers experienced throughout the workshops both in terms of the content and in terms of the interactions with the mentor.

This method of assessing the pedagogical problemsolving process by mapping it into distinct steps resembles methods used for analyzing expertlike problem-solving processes in the physics classroom. One of these methods is to map and assess the reasoning that the student provides, mapping both the execution of the major steps in the problem-solving process and the conceptual understanding reflected within each step. For example, an assessment rubric [91] designed for applying mathematics in realistic contexts (within the topic of mechanics) contained four assessment categories, following the stages of problem

TABLE I. Mapping episodes to steps in the pedagogical problem-solving process.

\begin{tabular}{|c|c|c|c|c|c|c|c|c|c|c|}
\hline \multirow[b]{2}{*}{ Stage of solution } & \multicolumn{10}{|c|}{ Episode number } \\
\hline & 1 & 2 & 3 & 4 & 5 & 6 & 7 & 8 & 9 & 10 \\
\hline \multicolumn{11}{|l|}{ Analysis } \\
\hline \multicolumn{11}{|l|}{ Planning action } \\
\hline \multicolumn{11}{|l|}{ Implementation } \\
\hline Evaluation & & & & & & & & & & \\
\hline
\end{tabular}

solving (model construction, data collection and analysis, interpretation, and validation). Assessment of stages of the problem-solving process has also been implemented in the context of research on problem-solving approaches [92]. Another method is the use of scoring rubrics for analyzing expertlike experimental investigation [93].

\section{B. Findings}

The findings will be described in three parts. The first part describes the characteristics of the enactment of the three workshops and discusses the extent to which they followed the intended modes of mentoring. The other two parts provide findings for the two research questions of this study. One examines the effectiveness of each of the workshops in providing opportunities for expert pedagogical problem solving to take place. The other investigates teachers' practices and perceptions in those workshops in which pedagogical problem-solving processes took place.

\section{Characterizing mentoring approaches in the workshops}

Figures 2(a)-2(c), show a summary of the time duration of information exchanges, for all sessions of workshops A, $\mathrm{B}$, and $\mathrm{C}$, as well as the distribution of work between home, class, and workshop meetings, in terms of active party and initiator.

As shown in Fig. 2(a), workshop A (minimal guidance) had the following characteristics.

- The teachers were active overall (home + class + workshop) about $70 \%$ of the time. A high level of teacher activity was especially evident in the face-toface meetings in the workshop (about $85 \%$ of the time).

- Overall, the teachers initiated information exchanges only about $30 \%$ of the time, while the leader initiated information exchanges about $80 \%$ of the time.

- In class, the teachers carried out the activities developed in the workshop during the meetings. There were only two class implementations, both initiated by the workshop leader. 


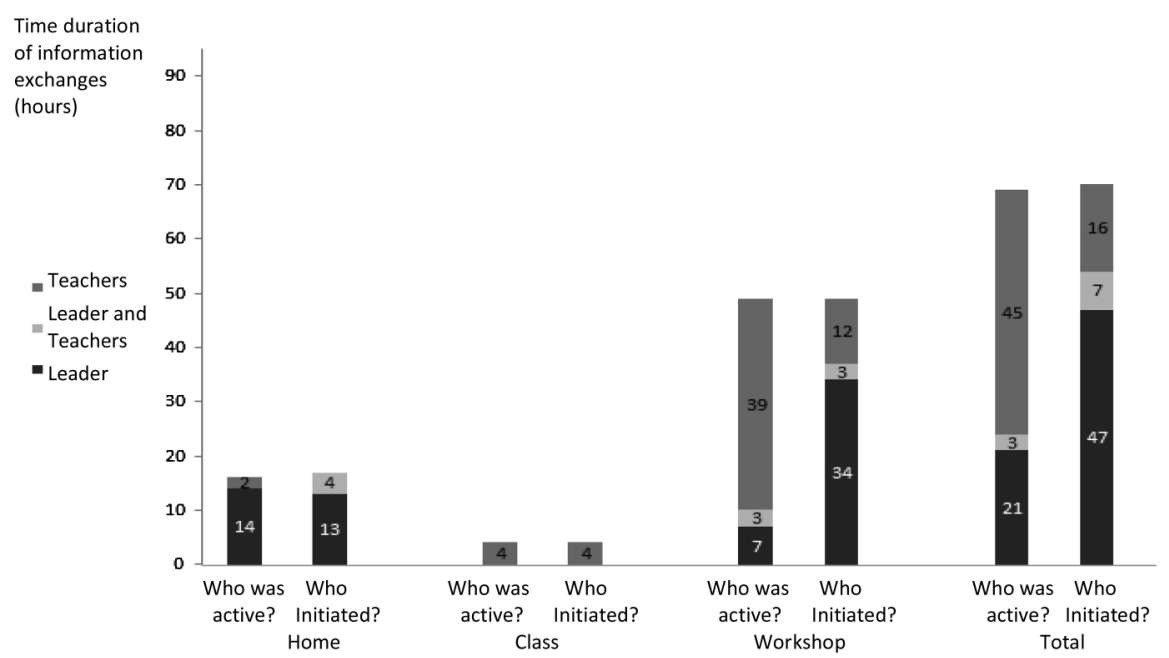

(a) Workshop A - minimal guidance

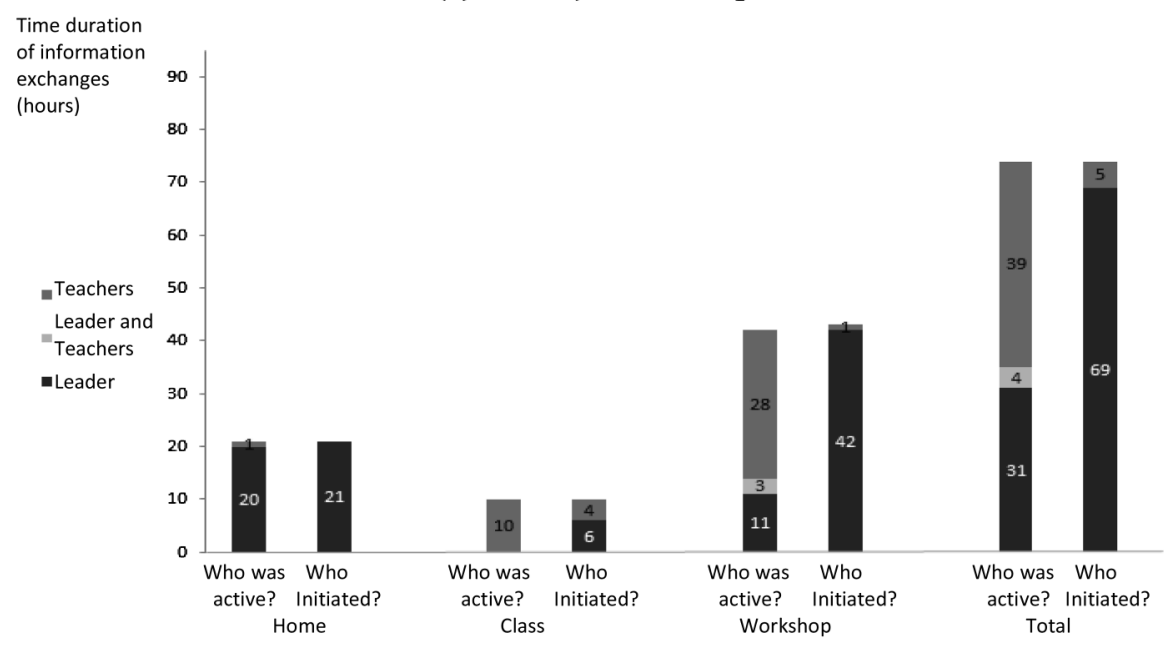

(b) Workshop B - maximal guidance

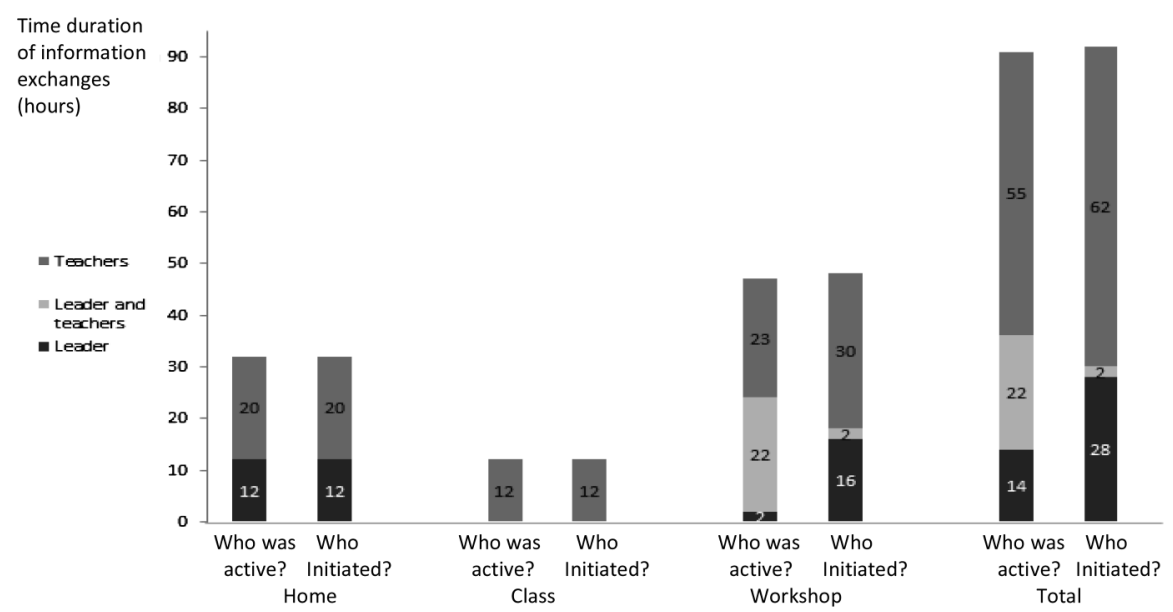

(c) Workshop C-The cognitive apprenticeship mentoring approach

FIG. 2. Frequency and time duration of information exchange by active party and initiator.

- The work carried out at home was done mainly by the leader summarizing former meetings, reviewing literature for discussion, and consequently determining how the cooperative work should evolve.
As mentioned above, in workshop A (minimal guidance) the plan was to provide minimal guidance: teachers were expected to take control of the problem-solving process. The leader was supposed to give support only if needed, 
without a systematic prespecified plan of guidance. The findings show that such support was indeed needed since the teachers were not very active in initiating information exchanges. Thus, when the workshop leader realized that the teachers were not taking control of the problem-solving process, she intervened by initiating information exchanges about $80 \%$ of the time.

Figure 2(b) indicates that in workshop B (maximal guidance):

- The teachers were active overall (home, class, workshop) about $60 \%$ of the time; in particular, they were active in the workshop about $75 \%$ of the time.

- They initiated information exchanges only about $10 \%$ of the time, while the leader initiated information exchanges about $90 \%$ of the time.

- The above pattern of activity was also evident in the workshop face-to-face meetings where the teachers were active $75 \%$ of the time, but hardly initiated any information exchanges on their own. The leader was the one who initiated the information exchanges nearly $100 \%$ of the time.

- There were five double-session implementations in the teachers' classes. The activities that were implemented in the classroom were prepared mostly by the workshop leader at home.

Judging from the data, the findings show that workshop B (maximal guidance) was as intended and involved tight guidance. The workshop leader initiated the information exchanges, and the control on planning and decisions was mostly in the hands of the workshop leader. The teachers hardly took any initiative on their own.

Figure 2(c) indicates that in workshop C (cognitive apprenticeship):

- The teachers were active in the workshop nearly $100 \%$ of the time, while the workshop leader was less active, about $50 \%$ of the time.

- The teachers initiated information exchanges $60 \%$ of the time, while the workshop leader initiated fewer information exchanges, only about $35 \%$ of the time.

- About $50 \%$ of the time the teachers and the workshop leaders interacted as indicated by the overlap of information exchanges.

- The teachers initiated the implementation of activities in their classes in six double period sessions.

- The teachers were active at home, preparing the activities to be implemented in class and analyzing them for collaborative reflection in the workshop. This work was mostly initiated by them (about 60\% of the time). The workshop leader was also active at home (about 30\% of the time), providing feedback and needed guidance to the teachers.

We conclude that the characteristics of teachers' behavior in workshop $\mathrm{C}$ were consistent with the "cognitive apprenticeship" approach that we described previously. In this approach teachers are expected to follow a prescribed customization process that explicates implicit expert customization processes (e.g., collecting and analyzing classroom data, interpretation of classroom events committed to the paradigm underlying the customized innovation). The workshop leader's role is to scaffold this process. In such a context teachers are expected to be active both in and out of the workshop and to initiate and carry out activities in their classes. The distribution of roles between the workshop leader and the teachers indicated by the data was aligned with the above description.

A comparison of the three workshops regarding the aspects described above sheds light on the teacher behavior resulting from these three modes of guidance. All workshops led to a high level of activity in the workshops' face-to-face meetings but workshop C (cognitive apprenticeship) led to a higher level of activity and initiation of information exchanges by the teachers as compared to the other two modes of guidance. While in workshop $\mathrm{C}$ the teachers initiated activities (as required by the approach), in the other workshops this aspect was weak. In workshop A with minimal guidance, the spontaneous behavior of the teachers exhibited reluctance to taking initiatives on their own, while in workshop B the tight guidance inhibited teachers' initiatives.

It is also interesting to compare the teachers' behavior in class. In workshop A, with minimal guidance, there was little implementation, showing that without support in this area, teachers shy away from trying out innovations requiring genuine changes in their classes. In workshop B, with tight guidance, the workshop leader required implementation and tailored the work in the workshop towards preparing the necessary materials for this implementation and indeed it took place. In workshop $\mathrm{C}$, that embodied the cognitive apprenticeship approach, the distribution of roles between the workshop leader and the teachers resulted in a larger number of actual implementations of the innovations in the classrooms. The implementations were preceded by customization efforts by the teachers, who prepared instructional materials for their classrooms. In addition, documentation of classroom practice served as follow-up activities in which teachers analyzed their experiences to share them with their peers.

\section{Assessing the performance of the expertlike pedagogical problem-solving process}

As described earlier (in the section "Characterizing the processes and products of the workshop via the episodes"), in order to operationally map the process of solving a fundamental pedagogical problem in a customization workshop, we formulated a prescribed pedagogical problem-solving process as measurable steps: analysis, planning, implementation, and evaluation.

These steps integrate those defined in the literature on physics problem solving [2,5] (a definition that highlights the analysis, planning, and evaluation steps) with those defined in the literature on teachers' problem solving, 
TABLE II. Workshop A (minimal guidance): Episodes mapped to pedagogical problem-solving steps. Implementation consists of both the development of instruction and materials as well as carrying those out in the classroom. In all tables, bold check marks refer to the classroom implementation.

\begin{tabular}{|c|c|c|c|c|c|c|c|c|c|c|c|c|c|c|c|c|c|c|c|c|c|}
\hline \multirow[b]{2}{*}{ Stage of solution } & \multicolumn{21}{|c|}{ Episode number } \\
\hline & 1 & 2 & 3 & 4 & 5 & 6 & 7 & 8 & 9 & 10 & 11 & 12 & 13 & 14 & 15 & 16 & 17 & 18 & 19 & 20 & 21 \\
\hline $\begin{array}{l}\text { Analysis } \\
\text { Planning action } \\
\text { Implementation } \\
\text { Evaluation }\end{array}$ & $\sqrt{ }$ & $\sqrt{ }$ & $\sqrt{ }$ & $\sqrt{ }$ & $\sqrt{ }$ & $\sqrt{ }$ & $\sqrt{ }$ & & & $\sqrt{ }$ & $\sqrt{ }$ & $\sqrt{ }$ & $\sqrt{ }$ & $\sqrt{ }$ & $\sqrt{ }$ & $\sqrt{ }$ & $\sqrt{ }$ & $\sqrt{ }$ & $\sqrt{ }$ & $\sqrt{ }$ & $\sqrt{ }$ \\
\hline
\end{tabular}

such as action-research steps [94]: (1) definition of a problem, (2) suggestion of a solution, (3) development and execution of instruction and materials, (4) evaluation and refinement.

As described earlier, the episodes were mapped to these steps.

This mapping enabled us to analyze, for each workshop, how many iterations took place in the process of contextrich pedagogical problem solving, which steps were executed, and which were not.

We also examined the extent to which the participants made use of earlier products that they had developed. For example, did workshop meetings respond to what actually happened in the teachers' classrooms? To that end, we also categorized the information exchanges by source of information, to map the variety of sources that contributed to the pedagogical problem-solving experience. In the context of this workshop there were three possible sources: "external source of information," when the workshop participants and/or the leader made use of the research literature, "teachers' general knowledge," when teachers' longterm accumulated experience served as the focal point in their arguments, and "internal source of information," when participants related to previous workshop products (e.g., classroom implementation of innovations that the teachers developed in the workshop and then documenting this implementation in a workshop meeting).

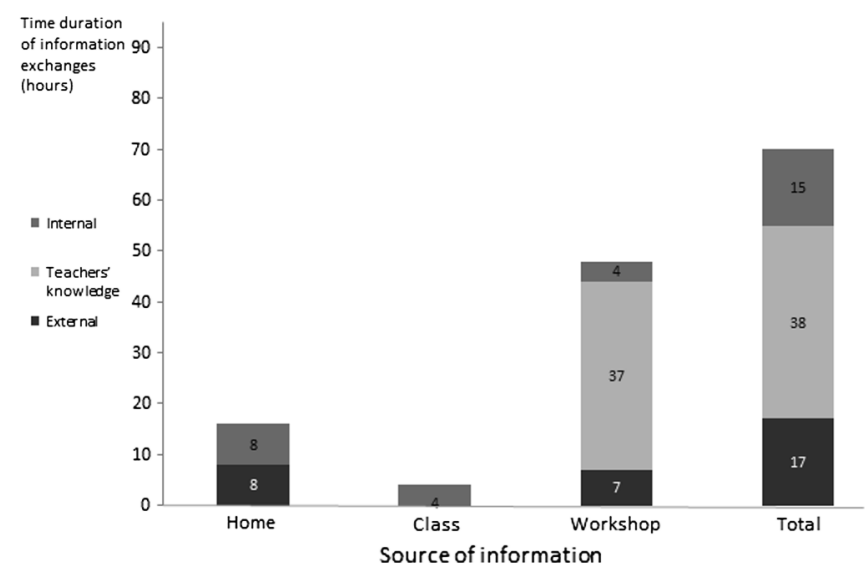

FIG. 3. Workshop A (minimal guidance): Information exchanges by source of information and location.
Since in an iterative problem-solving process we would expect previous workshop products to be a major source of information, this analysis can indicate to what extent the solution process was indeed iterative.

Execution of the pedagogical problem-solving processWorkshop A (minimal guidance).-We mapped the workshop episodes to the stages of the solution process, as shown in Table II, to identify which stages of the pedagogical problem-solving process were carried out, and how much iteration took place.

Table II shows that

(1) Two iterations occurred: the first ended in episode 12 , and the second did not involve analysis as a first stage.

(2) Analysis was the major component, most of it in the first quarter of the workshop.

(3) Planning was the shortest component in the workshop.

(4) Implementation in the classroom took place twice (the bold check marks).

We constructed histograms of the information exchanges in terms of source of information, as shown in Fig. 3, to determine the extent to which information flowed from the classroom to the workshop.

Only one-quarter of the total time in the workshop was spent relating to its previous products (source of information was "internal"). This happened mainly at home; the participants finalized work they had started in the workshop meetings and in the classroom where innovations customized in the workshop were implemented. In the workshop meetings themselves, the main source of information was teachers' general knowledge, not previous workshop products. Thus, the teachers relied upon their accumulated experience but did not continuously elaborate new ideas in the workshop.

Execution of the pedagogical problem-solving processWorkshop $B$ (maximal guidance).-We used the same method to map the workshop B episodes to the stages of the solution process, as shown in Table III.

Table III shows that

(1) Three partial iterations occurred: the first in episodes 1-4 (excluding analysis), the second in 10-13, and the third in 14-18 (these iterations excluded planning). 
TABLE III. Workshop B (maximal guidance): Episodes mapped to pedagogical problem-solving steps.

\begin{tabular}{|c|c|c|c|c|c|c|c|c|c|c|c|c|c|c|c|c|c|c|c|c|}
\hline \multirow[b]{2}{*}{ Stage of solution } & \multicolumn{20}{|c|}{ Episode number } \\
\hline & 1 & 2 & 3 & 4 & 5 & 6 & 7 & 8 & 9 & 10 & 11 & 12 & 13 & 14 & 15 & 16 & 17 & 18 & 19 & 20 \\
\hline $\begin{array}{l}\text { Analysis } \\
\text { Planning action } \\
\text { Implementation } \\
\text { Evaluation }\end{array}$ & $\sqrt{ }$ & $\sqrt{ }$ & $\sqrt{ }$ & $\sqrt{ }$ & $\sqrt{ }$ & $\sqrt{ }$ & $\sqrt{ }$ & $\sqrt{ }$ & $\sqrt{ }$ & $\sqrt{ }$ & $\sqrt{ }$ & $\begin{array}{l}\sqrt{ } \\
\sqrt{ }\end{array}$ & $\sqrt{ }$ & $\sqrt{ }$ & $\sqrt{ }$ & $\begin{array}{l}\sqrt{ } \\
\sqrt{ }\end{array}$ & $\sqrt{ }$ & $\sqrt{ }$ & $\sqrt{ }$ & $\sqrt{ }$ \\
\hline
\end{tabular}

(2) Repeated analysis was carried out in the workshop.

(3) Implementation, in the form of development of materials, was a more dominant component compared to workshop A (minimal guidance); most workshop participants reported four implementations of developed materials in the classroom (the bold check marks).

Figure 4 shows the time distribution and the number of information interchanges for the various sources of information:

Compared to workshop A (minimal guidance), much more of workshop B (maximal guidance) was based on its previous products than on teachers' general knowledge, both at home and in the classroom. However, the workshop meetings themselves were still based mostly on teachers' general knowledge.

The workshop leader did the majority of the work that was done at home [Fig. 2(b)], but the source of her work was different. In workshop A (minimal guidance), she spent half of her time editing resources from the research literature to present in the workshop, and the other half editing materials produced in the workshop. In workshop B (maximal guidance), most of the time was devoted to editing materials that the teachers had developed in the workshop.

Execution of the pedagogical problem-solving processWorkshop C (cognitive apprenticeship).-The mapping of workshop C episodes to the stages of the solution process is shown in Table IV.

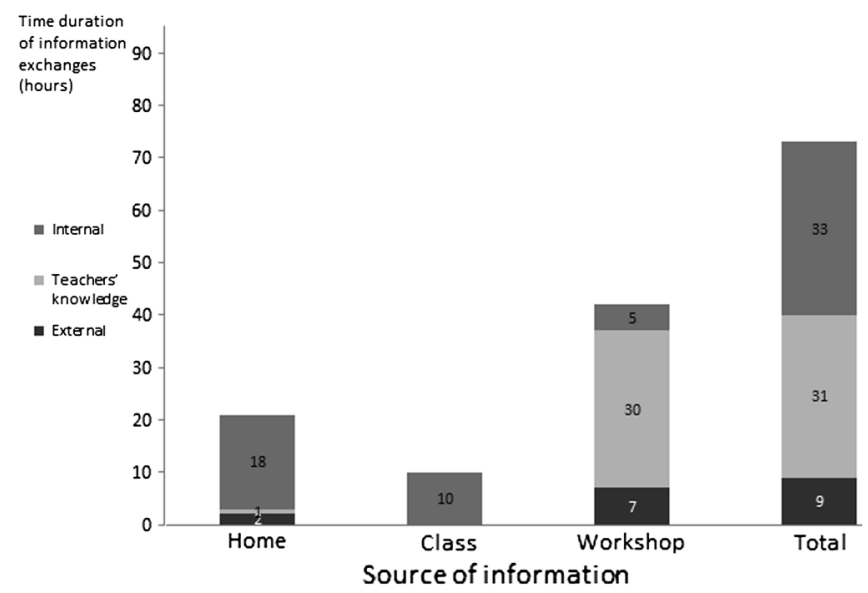

FIG. 4. Workshop B (maximal guidance): Information interchanges by source of information and location.
Workshop C was intended to follow a cognitive apprenticeship approach. The group work was structured by assigning roles (e.g., "documenter," "feedback provider," "summarizer"), and was also supported by group monitoring sessions (see Table IV).

Table IV shows the recurring execution of all stages of the pedagogical problem-solving process.

(1) At least six iterations occurred (in episodes 5-6, 9-10, 15-16, 17-18, 19-20, 21-22).

(2) In each iteration, all stages of the problem-solving process were carried out. (Analysis was dominant in the introductory summer workshop, excluded from the table.)

(3) In each iteration, developed materials were implemented in the classroom and reported on (the bold check marks).

(4) Workshop C introduced the stage of group or selfmonitoring of the execution of the process; this stage occurred three times. The first two episodes were initiated by the workshop leader whereas the other ones were initiated by the participants.

Figure 5 shows the time distribution and the number of information interchanges for the various sources of information in workshop C.

Compared to workshops A and B, the workshop meetings in workshop $\mathrm{C}$ were based to a much greater extent on previous products that resulted from internal interactions in the workshop: namely, teachers' documentation of their classroom experiences rather than on teachers' general knowledge.

A significant part of the work at home [Fig. 2(c)] was done by the teachers rather than the workshop leader, and the source of information for their work was mostly their classroom experience with innovative instructional ideas that resulted from the workshop discussions. The workshop leader's main role when working at home was providing feedback on materials produced by the teachers in the flag people cycles, as well as producing summaries of the issues that were raised in these cycles for the group to discuss.

Summary: Pedagogical problem-solving process enacted in each of the workshops.-We found that teachers did not spontaneously adopt an expertlike pedagogical problem-solving approach under the minimal guidance provided in workshop A (minimal guidance). Analysis was the major component of that workshop (eight episodes), and the number of planning episodes was small 
TABLE IV. Workshop C (cognitive apprenticeship): Episodes mapped to pedagogical problem-solving steps.

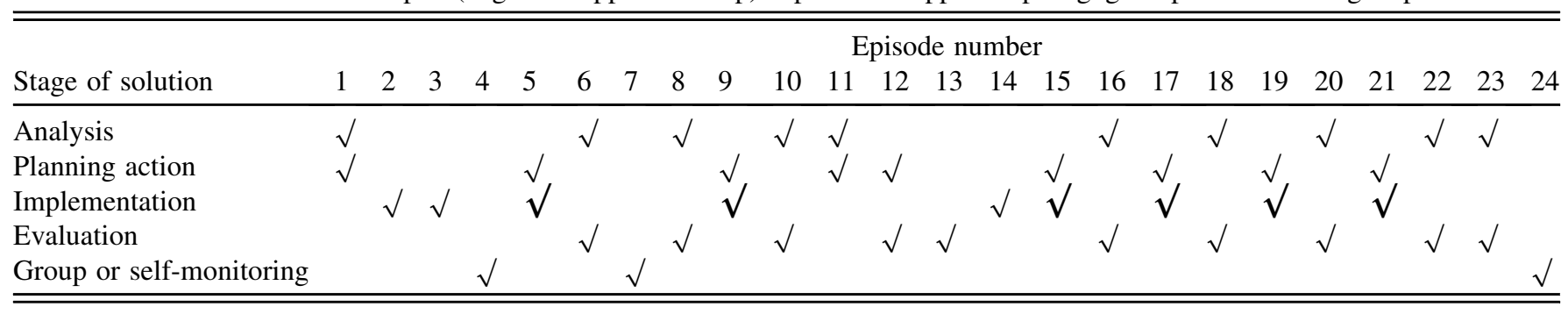

(three episodes). Only two iterations took place, both culminating in classroom implementations, but they did not evolve from each other since they were developed in parallel by two different teachers. On the whole, workshop meetings responded mainly to teachers' concerns that stemmed from experience accumulated throughout their careers, rather than to actual difficulties reported regarding classroom implementation of previous workshop products. They also responded, to some extent, to resources the workshop leader imported into the workshops.

In workshop B, where guidance was very tight, the picture was very different. Implementation, mainly development of materials, comprised the major component (nine episodes), and planning almost disappeared (one episode). Analysis and evaluation, respectively, preceded and followed the three classroom implementations as well as the development episodes that did not result in classroom implementation. In this case, evaluation took the form of development of evaluation tools that were not applied in classrooms and reflected teachers' concerns regarding the innovations. A positive difference from workshop A (minimal guidance) was that more teachers implemented the materials, one more iteration took place, and more information exchanges were based on previous workshop products.

Workshop C (cognitive apprenticeship) was the only one where the interaction between the workshop leader and the participating teachers was structured according to the

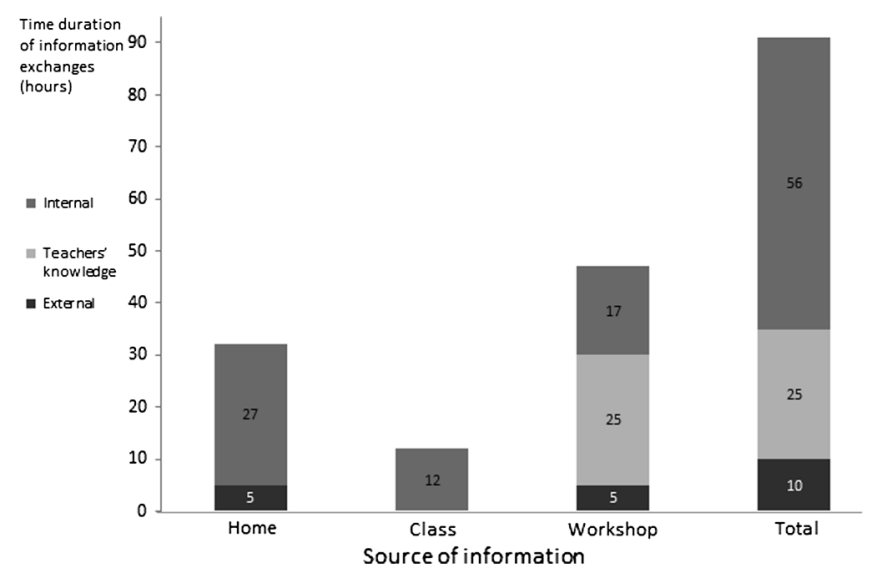

FIG. 5. Workshop C (cognitive apprenticeship): Information interchanges by source of information and location. cognitive apprenticeship approach. Here, the teachers engaged in a full and continuing expertlike pedagogical problem-solving process, interwoven with group processing episodes (three episodes).

More importantly, six iterations took place in the first year, and in each one all stages of the problem-solving process were carried out. In each iteration, materials were both developed and implemented in the classroom. Compared to workshops A (minimal guidance) and $\mathrm{B}$, a significantly higher proportion of workshop $\mathrm{C}$ (cognitive apprenticeship) responded to its previous products.

To summarize, the above analysis enabled us to answer our first research question. We were able to differentiate between pedagogical problem-solving approaches that took place in the workshops. Moreover, an expertlike pedagogical problem-solving process took place solely under the cognitive apprenticeship mentoring approach implemented in workshop C.

\section{Practice and perceptions developed throughout an expertlike pedagogical problem-solving process}

Our goal in this paper was to gain insights into how to achieve two goals of customization workshops: development of expertlike pedagogical problem solving and conceptual change. We expected that experiencing expertlike pedagogical problem solving would serve as a learning opportunity and lead to conceptual change. To exemplify how this process occurs, we now turn to our second research question: namely, what were the practices and perceptions developed by the participating teachers in workshops where an expertlike pedagogical problemsolving process took place?

We were able to study the practice and perceptions developed throughout an expertlike pedagogical problem-solving process only where such a process actually occurredwhere participants engaged in extensive iteration of all steps of the problem-solving process. Only workshop C (cognitive apprenticeship), which lasted two years, fulfilled that criterion. Eight teachers participated in workshop C.

We first characterized teachers' initial perceptions of the learning and instruction of problem solving using an openended questionnaire that was administered during the first meeting of the workshop. We then performed timedependent content analysis in which we looked for shared 
TABLE V. Workshop C (cognitive apprenticeship): Implemented innovations.

\begin{tabular}{|c|c|c|c|c|c|c|c|c|c|c|c|c|c|c|c|c|c|}
\hline \multirow[b]{3}{*}{ Instructional innovations } & \multicolumn{17}{|c|}{ Sequence number of flag person cycle } \\
\hline & \multicolumn{6}{|c|}{ Stage 1} & \multicolumn{4}{|c|}{ Stage 2} & & \multicolumn{6}{|c|}{ Stage 3} \\
\hline & 1 & 2 & 3 & 4 & 5 & 6 & 7 & 8 & 9 & 10 & 1 & 1 & 12 & 13 & 14 & 15 & 16 \\
\hline Solving problems guided by a problem-solving (PS) strategy & $\times$ & $\times$ & $\times$ & $\times$ & $\times$ & $\times$ & $\times$ & & & & & & & & & & \\
\hline Mapping execution of a problem-solving strategy & $x$ & & & & & $x$ & & & & $x$ & & & & & & & \\
\hline Choosing PS strategy level applied to solve problems & & & & & & & & & $x$ & & & & & & & & \\
\hline Eliciting problem-solving strategies from students & & & & & & & & $x$ & & & & & & & & & \\
\hline Self-diagnosis of problem solution using sample solution & $\times$ & $\times$ & $\times$ & $x$ & $\times$ & $\times$ & & $x$ & & & & & & & & & \\
\hline Mutual diagnosis of problem solution in diverse couples & & & $\times$ & & & & & & & & & & & & & & \\
\hline Drawing analogies between a correct and a mistaken solution & & & & & & & & & & $x$ & & & & & & $\times$ & \\
\hline Self-diagnosis of problem solution using a PS strategy & & & & & & & & & & & & & & $\times$ & & & $\times$ \\
\hline Self-diagnosis of problem solution using solution flow charts & & & & & & & & & & & & $x$ & $\times$ & & & & \\
\hline Self-diagnosis of problem solution using lists of mistakes & & & & & & & & & & & & & & & $\times$ & & \\
\hline
\end{tabular}

themes between consecutive cycles in the instruction and materials teachers developed and implemented. Following this analysis we identified three major stages that differed in terms of the nature of the materials developed. We analyzed the modifications the teachers introduced to the original innovations during successive iterations and looked for the dimensions and timetables for the changes in teachers' work. All implementation steps that included a classroom component (instruction and materials that were both developed and implemented in the teachers' classrooms) were reported during the documentation episode of each flag person cycle. This documentation served as the data to study how the teachers modified the original instructional innovations that they implemented.

Finally, we analyzed the relationship between evaluation or analysis and planning or implementation. To do so, we related the questions the flag person formulated for discussion (reflecting evaluation or analysis) to the instruction and materials that the flag person's documentation specified were developed and implemented (reflecting planning or implementation).

Table $\mathrm{V}$ lists the innovations that were implemented and reported on in the flag person cycles, and the number of the flag person cycles in which these documentation episodes took place, in chronological order. These cycles were categorized according to the three stages mentioned above. We marked which innovations were documented in each of these episodes.

Initial practice and perceptions.-An open-ended questionnaire served to study teachers' initial perceptions of the learning and teaching of problem solving. We were interested in answers that fell into the following categories.

(1) A category related to possible approaches to problem solving, in particular, to learning in this context (e.g., in response to the question "how should one cope with solving a difficult problem in Physics?," a teacher answered, "first identify the phenomenon involved and then the related laws"; or in response to "what do you perceive to be self-monitored learning?," another teacher answered, "independently solving novel problems").

(2) A category related to teachers' practices in the context of problem solving (e.g., answers to questions such as "how do you promote students' self-monitoring skills"; "how do you teach students to solve problems?"). Answers related to teachers' practices were further split into two major categories:

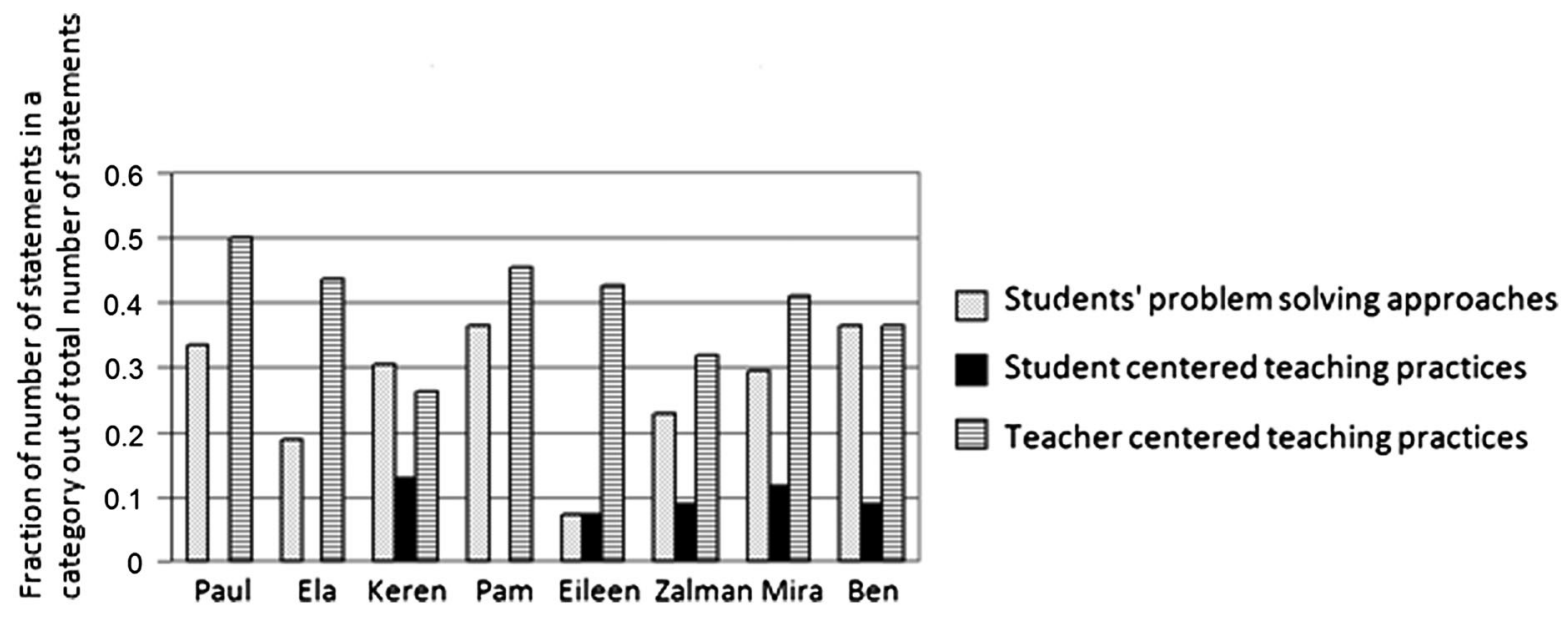

FIG. 6. A distribution of workshop participants' answers to the prequestionnaire. 
TABLE VI. Solution diagnosis form.

\begin{tabular}{llll}
\hline \hline Step & Exists? & Correct? & Explain \\
\hline Focus the physics & & & \\
Plan & & \\
Execute & & \\
Evaluate & & \\
\hline \hline
\end{tabular}

(2a) Student centered practices-encouraging students to practice the target approaches to problem solving (e.g., in response to the question "how should one cope with solving a difficult problem in Physics?," a teacher answered, "I should guide students to break the problem down into sub-problems"; or, in response to the question, "how do you promote students' self-monitoring skills?," a teacher answered "I require evaluation of the likelihood of the final solution").

(2b) Teacher centered practices that were not aimed at encouraging students to practice the target approaches (e.g., a teacher answered "how should one cope with solving a difficult problem in Physics?," with, "I should illustrate through a demonstration"; or, in response to the question "how do you promote students' self-monitoring skills?," a teacher answered, "give them tests").

As is clear from the above, the questions enabled answers that could be assigned to all categories. Figure 6 shows for each of the workshop participants the fraction of statements expressed in each category out of the total number of statements that each of the teachers expressed (miscellaneous statements are not included, all names have been changed).

We observed a common trend in teachers' answers: most seemed to possess an elaborate portrayal of the problemsolving process and its relation to learning (students' problem-solving approaches category). However, most of the teachers' statements portrayed teacher centered teaching practices rather than student centered ones; thus, their teaching practices did not coincide with their understanding of students' learning while solving problems.

Modifications in instruction and materials reported in the flag person documentation.-Next, we looked for shared themes between consecutive cycles, in instructional strategies and materials. We found three major developmental stages.

Stage 1: Year one, first semester: In this stage (cycles 1-7) the teachers asked their students to follow a strategy (steps in a problem solution) when solving problems or to diagnose their own solutions based on the teacher's solved example. These instructional strategies were presented by the workshop leader in the summer workshop. The modifications they made to the instructional innovations introduced in the summer workshop focused on adapting strategies to different topics and writing solved examples that matched these strategies. For example, a specific strategy introduced in the summer introductory workshop consisted of five steps for solving problems aligned with a problem-solving strategy suggested in the literature [2]: (a) focus the problem, (b) describe the physics, (c) plan the solution, (d) execute the plan, (e) evaluate the answer.

The teachers adapted this strategy using the topic of work and energy. For example, the detailed instruction in step (c) was "Divide the problem into sub-problems in order to find unknown variables needed to find the target quantity." The teachers added the following to this instruction: "For each sub-problem, write the known and unknown variables in an equation representing the principle of energy conservation." They considered the new instruction as applicable to a whole set of problems dealing with energy conservation.

The teachers did transform their previous methods of teaching in that they required their students to perform steps (to diagnose their solutions, to follow a strategy) that they had formerly only hoped students would do with no explicit guidance. Yet the teachers adapted the strategies to conform more closely to traditional instruction. On the one hand, they provided guidance that was detailed in comparison to the original innovations, reflecting a tendency to go with the "spoon-fed" approach. On the other hand, they abandoned important elements of the original instructional strategies, such as group work, modeling the strategies in their sample solutions, and using context-rich problems (they used traditional textbook problems).

Stage 2: First year, second semester: In this stage (cycles 8-10) the teachers' customization efforts focused on making students more comfortable with the instructional innovations, as well as addressing the diversity in their classrooms. For example, in flag person cycle 8 they familiarized students with problem-solving strategies. They asked students to suggest problem-solving steps and then vote on which of these steps to include in a strategy to be used in their class. Then they held class discussions regarding how to organize problem solving into its main steps, and the pros and cons of working with strategies.

In flag person cycle 9, the teachers addressed students' diversity by developing two levels of more and less detailed strategy the students could choose between. For example, the instruction "divide ..." mentioned previously was elaborated in the more detailed strategy to include guiding questions such as, "Does the body change its motion (linear or curved trajectory, constant or changing speed)? Do the forces on it change-are they conservative? Do they perform work?" The detailed strategy was more suitable to students who needed a more confined set of possible decisions. The students were given the choice of which strategy to choose and were asked to reflect on their choices.

Stage 3: Year two: In stage 3 (cycles 11-16) the teachers' customization reflected a more elaborated and refined understanding of the nature of the learning process involved in problem solving and teachers' interventions 
that can support it. For example, in cycles 13 and 16 the teachers reported assigning a self-diagnosis activity designed to focus the students' attention on diagnosing their use of the strategy rather than comparing their solution to the teacher's sample solution. In this activity the students were assigned a context-rich problem as homework, and were required to solve it by following specific strategy guidelines. The strategy was written in the format of requirements for the presentation of the solution. For example, the instruction for the planning step mentioned earlier, "Divide the problem into sub-problems," was modified to "Present the sub-problems you identified: choice of a body, listing of known and unknown quantities in the sub-problem ...." Then, in class, students were asked to fill in a diagnosis form focused on the strategy steps, as shown in Table VI.

In the "Exists?" column the students were asked to check off the steps that had been done, in the "Correct?" column to identify whether these parts were right or wrong, and in the "Explain" column to write an explanation of what went wrong in the solution.

This activity guided students to diagnose the stage in problem solving where their mistakes occurred, rather than merely identifying their mistakes. The strategy was written in the format of requirements for the presentation of the solution, rather than as directions for consecutive steps in the solution process.

Other innovative approaches were tried as well in this stage, such as how to guide students in the self-diagnostic process. These included drawing solution flow charts and providing lists of common mistakes found in student solutions so students could compare their own mistakes.

Relationship between the modifications in instruction and materials and flag person questions.-Secondly, we studied how the pedagogical problem-solving steps affected each other by analyzing the relationship between the questions the flag people formulated and the instruction and materials they reported having developed and implemented.

Stage 1 (cycles 1-7 in the first semester) was a direct continuation of the analysis that took place in the summer workshop. The teachers made use of the main innovations introduced in that workshop.

The main issues discussed within each flag person cycle were defined by the flag person who phrased questions for discussion. Throughout the first stage, these questions dealt with "how," issues focusing on students' affective attitudes toward the innovation tried in class (e.g., "Should I require my students to use a strategy in their problem solving, or should I just advise them to do so?") and classroom diversity (e.g., “The strong students don't want to cooperate with the weak ones; how do you suggest handling this problem?").

The instructional innovations developed in stage 2 (described above) indeed responded to the concerns raised by these questions. At the end of this stage (i.e., at the end of the first year) the teachers voiced ambivalent feelings. On the one hand, they expressed satisfaction-"I acquired tools to develop my students' ability to slowly and confidently perform a critical review of their work ... their responsibility and involvement is higher." On the other hand, they felt that they were still at the beginning of the road. They questioned the utility of basing self-diagnosis on a solved example, since in such a situation there is no need for revision of the solution. These hesitations were accompanied by a retreat to earlier positions. There was a revival of ideas that contradicted the whole spirit of the workshop and had seemingly been abandoned as early as the initial summer workshop, such as "How to prevent students from making mistakes." At that point, the teachers asked to

TABLE VII. Pedagogical problem-solving steps embedded in the flag person framework.

\begin{tabular}{|c|c|c|c|c|}
\hline \multirow[b]{2}{*}{ Flag person stages } & \multicolumn{4}{|c|}{ Problem-solving steps } \\
\hline & Analysis & Planning action & Implementation & Evaluation \\
\hline $\begin{array}{l}\text { Flag person } \\
\text { documentation }\end{array}$ & & $\begin{array}{l}\text { Formulating and } \\
\text { reporting activity } \\
\text { goals }\end{array}$ & $\begin{array}{l}\text { Reporting classroom } \\
\text { instruction }\end{array}$ & $\begin{array}{l}\text { Reporting data collected } \\
\text { regarding students' attitudes } \\
\text { and performance }\end{array}$ \\
\hline Peer feedback & $\begin{array}{l}\text { Formulating concerns } \\
\text { about class experience }\end{array}$ & $\begin{array}{l}\text { Proposing } \\
\text { alternatives }\end{array}$ & $\begin{array}{l}\text { Requesting to } \\
\text { elaborate report }\end{array}$ & \\
\hline $\begin{array}{l}\text { Flag person } \\
\text { questions }\end{array}$ & & & & $\begin{array}{l}\text { Formulating concerns } \\
\text { about class experience }\end{array}$ \\
\hline Discussion & $\begin{array}{l}\text { Interpreting concerns } \\
\text { about class experience }\end{array}$ & Suggesting response & & \\
\hline $\begin{array}{l}\text { Decisions based on } \\
\text { summary assembled } \\
\text { by workshop leader }\end{array}$ & & $\begin{array}{l}\text { Determining future } \\
\text { directions }\end{array}$ & & \\
\hline $\begin{array}{l}\text { Workshop meetings } \\
\text { in between flag } \\
\text { person cycles }\end{array}$ & & & $\begin{array}{l}\text { Developing instruction } \\
\text { and related materials }\end{array}$ & \\
\hline
\end{tabular}


continue the workshop for another year, during which time they hoped to write classroom materials and carry out a systematic evaluation of one mode of instruction.

In stage 3, the teachers reexamined goals that had, on the face of it, already been agreed upon in the introductory workshop more than a year earlier. For example, one teacher posed the following question, after trying an activity to teach self-diagnosis based on strategy: "The activity required students to find and correct their mistakes. I see three different groups: those who are willing and able, those who tried but did not succeed, and those who did not bother. What, if anything, do you think students from the second group gained from taking part in the activity?" It is our understanding that this teacher was weighing learning skills versus content knowledge as goals of instruction. The teachers were honest about their doubts, although, as described earlier, the instruction they developed and implemented deviated significantly from former class routines and reflected a strong commitment to achieving new goals.

It is clear that these questions had an impact on the implemented instruction and vice versa. Initially, teachers customized innovations to different physics topics. At that stage the questions reflected a consensus on goals, and the only issue at hand was the means to achieve them; thus. implementation focused on addressing students' affective attitudes. As time passed, and the goals were materialized in the implementation, teachers acquired a deeper understanding of the meaning and implications of the goals, and there was a need to reexamine them. This examination resulted in focusing the guidance of students on revision rather than on the whole problem-solving process. While doing so, the teachers dared to do more and more nontraditional things in the classroom. The changes, however, emerged over a very long time period and ranged along several dimensions.

\section{CONCLUSION}

The goal of this study was to identify mentoring approaches that foster expert pedagogical problem solving and to empirically examine the hypothesis that customization workshops that employ the mentoring approach of cognitive apprenticeship effectively lead teachers to enact expertlike pedagogical problem solving.

To do so, we studied the pedagogical problem-solving process that took place in three customization workshops that differed in their mentoring approaches.

We first analyzed the actual distribution of roles between the workshop leader and the participating teachers to determine the mentoring approach used in each workshop. This analysis showed that workshop A (minimal guidance) was a version of the "minimal guidance" approach to involving teachers in pedagogical problem solving. However, when the workshop leader realized that the teachers were not taking control of the problem-solving process, she took control back and initiated the workshop activities. Workshop B (maximal guidance) tended toward the "spoon-fed" approach in that decisions were mostly in the hands of the workshop leader. Workshop C took a "cognitive apprenticeship" approach in developing expertlike pedagogical problem solving. Scaffolding was provided by requiring teachers to follow an explicit "strategy" that externalized expertlike pedagogical problem solving. In addition, group discussions were structured through role allocation to provide opportunities for peer and/or self-explanation and evaluation.

To answer our first research question regarding the extent to which each of the mentoring approaches led to the development of an expertlike pedagogical problemsolving process, we used two methods to examine this process in each workshop. First, we analyzed the sources of information for all information exchanges that took place in each workshop. Second, we mapped all workshop episodes to the principal steps of the pedagogical problemsolving process.

We found that teachers did not employ an expertlike pedagogical problem-solving approach under the minimal guidance provided in workshop A (minimal guidance). Not all problem-solving steps were executed; few cycles of the problem-solving process occurred, and the existing ones did not evolve out of each other. Workshop meetings did not rely, to any significant extent, on previous workshop products, such as on lessons learned from classroom implementation of customized innovations,

Workshop B (maximal guidance) differed from workshop A (minimal guidance) in that more teachers implemented the materials, more iterations took place, and more information exchanges were based on previous workshop products. Yet, planning was almost entirely absent and some of the innovations customized in the workshop and the evaluation tools developed in the workshop were not implemented.

Only in workshop $\mathrm{C}$, in which the interaction between the workshop leader and the participating teachers was structured according to the cognitive apprenticeship approach, did the teachers engage in a full and continuing expertlike pedagogical problem-solving process. The problem-solving process was interwoven with group processing episodes.

To answer our second research question about the practices and perceptions developed by the participating teachers in a workshop where an expertlike pedagogical problem-solving process took place, we examined the changes in curricular products developed during the two years of this workshop, workshop C.

We found substantial improvement in teachers' practice and perceptions. Teachers persisted in tailoring existing research-based curricula to suit their needs, while changing perceptions and practices to promote students' expertlike problem solving. They experimented more boldly and more often with nontraditional methods in the classroom.

However, we found that it took a very long time for teachers to internalize the workshop goals. While in 
early workshop discussions it seemed that there was a consensus on goals, leaving only a need to consider means, as time passed and the goals were materialized through their implementation, teachers reexamined these goals and altered their understanding of the problem-solving process along with their instructional role within it. This finding corroborates the work of Fullan and Stiegelbauer [95] who found that it takes a minimum of two years of professional development for a teacher to fundamentally change his or her approach.

These findings allow us to suggest a form of mentoring that indeed leads to the enactment of an expertlike problem-solving process. Based on these findings, we conclude that the most effective mentoring approach examined here was the cognitive apprenticeship approach taken in the flag person framework, the backbone structure of workshop C. In the flag person framework, group work is structured by assigning roles (e.g., documenter, feedback provider, summarizer) and is supported by group processing sessions. The implicit or tacit problem-solving strategies of experts are externalized via the mentor's prescribing and enforcing of an expertlike problem-solving strategy. Scaffolding is provided by guiding the teachers in their pursuit of the prescribed pedagogical problemsolving process as it is embedded in the definition of the flag person framework. This process comprised analysis, planning, implementation, and evaluation stages as shown in Table VII.

To summarize, this study shows that to turn fundamental pedagogical problems into an effective vehicle in teachers' professional development, one needs to carefully structure their exploration. In particular, this study suggests that applying cognitive apprenticeship in customization workshops, in a manner similar to its application in the teaching of expertlike problem solving in the physics classroom, can effectively scaffold teachers' exploration of fundamental pedagogical problems in the context of customization workshops.

\section{ACKNOWLEDGMENTS}

We would like to thank the teachers who participated in this study. Their professional integrity enabled us to carry out this work.
[1] A. Van Heuvelen, Learning to think like a physicist: A review of research-based instructional strategies, Am. J. Phys. 59, 891 (1991).

[2] K. Heller, Competent Problem Solver: Calculus Version (Thomson, Mason, OH, 2006).

[3] P. Heller and M. Hollabaugh, Teaching problem solving through cooperative grouping, Part 2: Designing problems and structuring groups, Am. J. Phys. 60, 637 (1992).

[4] J. P. Mestre, R. J. Dufresne, W. J. Gerace, P. T. Hardiman, and J.S. Touger, Promoting skilled problem-solving behavior among beginning physics students, J. Res. Sci. Teach. 30, 303 (1993).

[5] F. Reif, Millikan Lecture 1994: Understanding and teaching important scientific thought processes, Am. J. Phys. 63, 17 (1995).

[6] W. J. Leonard, R. J. Dufresne, and J.P. Mestre, Using qualitative problem-solving strategies to highlight the role of conceptual knowledge in solving problems, Am. J. Phys. 64, 1495 (1996).

[7] E. Bagno and B.S. Eylon, From problem solving to a knowledge structure: An example from the domain of electromagnetism, Am. J. Phys. 65, 726 (1997).

[8] E.F. Redish, Teaching Physics with the Physics Suite (Wiley, Hoboken, NJ, 2003).

[9] L.C. McDermott and P.S. Shaffer, and the Physics Education Group at the University of Washington, Tutorials in Introductory Physics (Prentice-Hall, Upper Saddle River, NJ, 2002), 1st ed.

[10] P. S. Shaffer and L. C. McDermott, Research as a guide for curriculum development: An example from introductory electricity. Part II: Design of instructional strategies, Am. J. Phys. 60, 1003 (1992).

[11] P. Laws, Millikan Lecture 1996: Promoting active learning based on physics education research in introductory physics courses, Am. J. Phys. 65, 14 (1997).

[12] D. P. Jackson, P. W. Laws, and S. Franklin, Explorations in Physics: An Activity-Based Approach to Understanding the World (Wiley, New York, 2003).

[13] C. H. Crouch and E. Mazur, Peer Instruction: Ten years of experience and results, Am. J. Phys. 69, 970 (2001).

[14] E. Etkina, A. Karelina, and M. Ruibal-Villasenor, How long does it take? A study of student acquisition of scientific abilities, Phys. Rev. ST Phys. Educ. Res. 4, 020108 (2008).

[15] R. J. Beichner, J. M. Saul, D. S. Abbott, J. J. Morse, D. L. Deardorff, R. J. Allain, S. W. Bonham, M. H. Dancy, and J.S. Risley, The Student-Centered Activities for Large Erollment Undergraduate Programs (SCALE-UP) project, in Research-Based Reform of University Physics, edited by E. F. Redish and P. J. Cooney [Rev. PER Vol. 1, http:// www.per-central.org/document/ServeFile.cfm?ID=4517].

[16] A. Van Heuvelen and E. Etkina, The Physics Active Learning Guide (Addison Wesley, San Francisco, CA, 2006).

[17] M. Wells, D. Hestenes, and G. Swackhamer, A modeling method for high school physics instruction, Am. J. Phys. 63, 606 (1995).

[18] E. Yerushalmi, C. Henderson, K. Heller, P. Heller, and V. Kuo, Physics faculty beliefs and values about the teaching and learning of problem solving. I. Mapping the common core, Phys. Rev. ST Phys. Educ. Res. 3, 020109 (2007). 
[19] E. Yerushalmi, E. Cohen, K. Heller, P. Heller, and C. Henderson, Instructors' reasons for choosing problem features in a calculus-based introductory physics course, Phys. Rev. ST Phys. Educ. Res. 6, 020108 (2010).

[20] K. Cummings, J. Marx, R. Thornton, and D. Kuhl, Evaluating innovation in studio physics, Am. J. Phys. 67, S38 (1999).

[21] R. R. Hake, Interactive-engagement versus traditional methods: A six-thousand-student survey of mechanics test data for introductory physics courses, Am. J. Phys. 66, 64 (1998).

[22] M. Neuschatz, M. McFarling, and S. White, "Reaching the Critical Mass: The Twenty Year Surge in High School Physics," American Institute of Physics, 2008, http:// www.aip.org/statistics/trends/reports/hs05report.pdf

[23] C. Henderson and M. H. Dancy, Impact of physics education research on the teaching of introductory quantitative physics in the United States, Phys. Rev. ST Phys. Educ. Res. 5, 020107 (2009).

[24] C. Henderson and M. H. Dancy, Physics faculty and educational researchers: Divergent expectations as barriers to the diffusion of innovations, Am. J. Phys. 76, 79 (2008).

[25] B. Shayshon, "The professional development of teacherleaders," Ph.D. thesis, University of Salford, 2001.

[26] G. Leinhardt, On teaching, in Advances in Instructional Psychology, edited by R. Glazer (Erlbaum, Hillsdale, NJ, 1993), p. 1.

[27] C. Henderson, The challenges of instructional change under the best of circumstances: A case study of one college physics instructor, Am. J. Phys. 73, 778 (2005).

[28] D. Hammer, Teacher inquiry, in Inquiring into Inquiry Learning and Teaching in Science, edited by J. Minstrell and E. van Zee (American Association for the Advancement of Science, Washington, DC, 2000), p. 184.

[29] J. H. Van Driel, N. Verloop, H. Inge Van Werven, and H. Dekkers, Teachers' craft knowledge and curriculum innovation in higher engineering education, High. Educ. 34, 105 (1997).

[30] C. Turpen and N. Finkelstein, Not all interactive engagement is the same: Variations in physics professors' implementation of peer instruction, Phys. Rev. ST Phys. Educ. Res. 5, 020101 (2009).

[31] B.S. Eylon, H. Berger, and E. Bagno, An evidence-based continuous professional development program on knowledge integration in physics: A study of teachers' collective discourse, Int. J. Sci. Educ. 30, 619 (2008).

[32] L. S. Shulman, Communities of Learners and Communities of Teachers (Mandel Institute, Jerusalem, 1997).

[33] S. Loucks-Horsley, N. B. Love, K. E. Stiles, S. E. Mundry, and P. W. Hewson, Designing Professional Development for Teachers of Science and Mathematics (Corwin Press, Thousand Oaks, CA, 1998).

[34] R. T. Putnam and H. Borko, What do new views of knowledge and thinking have to say about research on teacher learning?, Educ. Res. 29, 4 (2000).

[35] P. Grimmett, A. Mackinnon, G. Erickson, and T. Reicken, Reflective practice in teacher education, in Encouraging Reflective Practice in Education, edited by R. Clift, W. Houston, and M. Pugach (Teachers College Press, New York, 1990), p. 20.
[36] W. Louden, Understanding reflection through collaborative research, in Understanding Teacher Development, edited by A. Hargreaves and M. G. Fullan (Teacher College Press, New York, 1992), p. 178.

[37] J. H. Van Driel, D. Beijaard, and N. Verloop, Professional development and reform in science education: The role of teachers' practical knowledge, J. Res. Sci. Teach. 38, 137 (2001).

[38] B.S. Eylon and E. Bagno, Research-design model for professional development of teachers: Designing lessons with physics education research, Phys. Rev. ST Phys. Educ. Res. 2, 020106 (2006).

[39] L. Gerard, M. Spitulnik, and M. C. Linn, Teacher use of evidence to customize inquiry science instruction, J. Res. Sci. Teach. 47, 1037 (2010).

[40] E. Prather and G. Brissenden, Development and application of a situated apprenticeship approach to professional development of astronomy instructors, Astron. Educ. Rev. 7, 1 (2008).

[41] T. Bartiromo and E. Etkina, Implementing reform: Teachers' beliefs about students and the curriculum, AIP Conf. Proc. 1179, 89 (2009).

[42] D. Maloney, Research on problem solving: Physics, in Handbook of Research on Science Teaching and Learning, edited by D. Gabel (MacMillan, New York, 1994).

[43] D. Maloney, An overview of physics education research on problem solving, in Getting Started in PER, Reviews in PER Vol. 2, edited by C. Henderson and K. A. Harper (American Association of Physics Teachers, College Park, MD, 2011).

[44] F. Reif, Applying Cognitive Science to Education: Thinking and Learning in Scientific and Other Complex Domains (MIT Press, Cambridge, MA, 2008).

[45] K. Carter and W. Doyle, Preconceptions in learning to teach, Educ. Forum 59, 186 (1995).

[46] M.F. Pajares, Teachers' beliefs and education research: Cleaning up a messy construct, Rev. Educ. Res. 62, 307 (1992).

[47] J. Nespor, The role of beliefs in the practice of teaching, J. Curric. Stud. 19, 317 (1987).

[48] D. Schon, The Reflective Practitioner: Toward a New Design for Teaching and Learning in the Professions. (Jossey-Bass, San Francisco, CA, 1987).

[49] D. C. Berliner, In pursuit of the expert pedagogue, Educ. Res. 15, 5 (1986).

[50] D.C. Berliner, Expertise: The wonder of exemplary performances, in Creating Powerful Thinking in Teachers and Students, edited by J.N. Mangieri and C. C. Block (Holt, Rinehart and Winston, Ft. Worth, TX, 1994), p. 161.

[51] H. Borko, J. Jacobs, E. Eiteljorg, and M. E. Pittman, Video as a tool for fostering productive discussions in mathematics professional development, Teach Teach. Educ. 24, 417 (2008).

[52] A. Newell and H. A. Simon, Human Problem Solving (Prentice-Hall, Englewood Cliffs, NJ, 1972).

[53] A. Van Heuvelen, Experiment problems for mechanics, Phys. Teach. 33, 176 (1995).

[54] RELATE real-world problems, http://relate.mit.edu/ teaching/real-world-problems/. 
[55] Activity Based Physics Thinking Problems in Physics, http://www.physics.umd.edu/perg/abp/think/.

[56] B. Eylon and E. Bagno, Professional development of physics teachers through long-term in service programs: The Israeli experience, in The Changing Role of Physics Department in Modern Universities, edited by E. F. Redish and J. S. Rigden (AIP, Woodbury, NY, 1997), p. 299.

[57] R. Sternberg and J. Horvath, A prototype view of expert teaching, Educ. Res. 24, 9 (1995).

[58] C. Singh, When physical intuition fails, Am. J. Phys. 70, 1103 (2002).

[59] D. Fortus, The importance of learning to make assumptions Sci. Educ. 93, 86 (2009).

[60] J. H. Larkin, Processing information for effective problem solving, Eng. Educ. 70, 285 (1979).

[61] P. Kohl and N. Finkelstein, Patterns of multiple representation use by experts and novices during physics problem solving, Phys. Rev. ST Phys. Educ. Res. 4, 010111 (2008).

[62] M. T. H. Chi, P. J. Feltovich, and R. Glaser, Categorization and representation of physics problems by experts and novices, Cogn. Sci. 5, 121 (1981).

[63] M. T. H. Chi and K. A. Van Lehn, The content of physics self-explanations, J. Learn. Sci. 1, 69 (1991).

[64] J. H. Larkin, J. McDermott, D. P. Simon, and H. A. Simon, Expert and novice performance in solving physics problems, Science 208, 1335 (1980).

[65] J.H. Larkin, Skilled problem solving in physics: A hierarchical planning model, J. Struct. Learn. 1, 271 (1980).

[66] A.H. Schoenfeld, Learning to think mathematically: Problem solving, metacognition, and sense making in mathematics, in Handbook of Research on Mathematics Teaching and Learning, edited by D. A. Grouws (MacMillan, New York, 1992), p. 334.

[67] J.H. Larkin and F. Reif, Understanding and teaching problem solving in physics, Eur. J. Sci. Educ. 1, 191 (1979).

[68] F. Reif and J.I. Heller, Knowledge structure and problem solving in physics, Educ. Psychol. 17, 102 (1982).

[69] J. Tuminaro and E. Redish, Elements of a cognitive model of physics problem solving: Epistemic games, Phys. Rev. ST Phys. Educ. Res. 3, 020101 (2007).

[70] J.P. Smith, A. A. DiSessa, and J. Roschelle, Misconceptions reconceived: A constructivist analysis of knowledge in transition, J. Learn. Sci. 3, 115 (1994).

[71] C. Bereiter and M. Scardamalia, Intentional learning as a goal of instruction, in Knowing, Learning, and Instruction: Essays in Honor of Robert Glaser, edited by L. B. Resnick (Erlbaum, Hillsdale, NJ, 1989), p. 361.

[72] E. Kim and S. Pak, Students do not overcome conceptual difficulties after solving 1000 traditional problems, Am. J. Phys. 70, 759 (2002).

[73] S.M. Wilson, L.S. Shulman, and A.E. Richert, "150 different ways" of knowing: Representations of knowledge in teaching, in Exploring Teachers' Thinking, edited by J. Calderhead (Cassell Educational Limited, London, 1987), p. 104.

[74] M. Ben-Peretz, Teacher stress and curriculum innovations in science teaching, in Science Education: From Theory to
Practice, edited by A. Hofstein, B. Eylon, and G. Giddings (Weizmann Institute of Science, Rehovot, Israel, 1995), p. 429.

[75] C. Henderson and M.H. Dancy, Barriers to the use of research-based instructional strategies: The influence of both individual and situational characteristics, Phys. Rev. ST Phys. Educ. Res. 3, 020102 (2007).

[76] A. H. Schoenfeld, Toward a theory of teaching in context, Issues Educ. 4, 1 (1998).

[77] A. Collins, D. Joseph, and K. Bielaczyc, Design research: Theoretical and methodological issues, J. Learn. Sci. 13, 15 (2004).

[78] R. M. Garrett, Issues in science education: Problemsolving creativity and originality, Int. J. Sci. Educ. 9, 125 (1987).

[79] B. Eylon, J. Singer, and U. Ganiel, Problem solving in high school--A necessary addition to the physics curriculum, in Proceedings of the 9th Conference on Physics Education: The Many Faces of Teaching and Learning Mechanics, Utrecht, Netherlands, 1984, edited by P.L. Lijnse (Unesco, Paris, 1985), p. 312.

[80] A. Schoenfeld, When good teaching leads to bad results: The disasters of "well taught" mathematics classes, Educ. Psychol. 23, 145 (1988).

[81] A. Collins, J. S. Brown, and S.E. Newman, Cognitive apprenticeship: Teaching the crafts of reading, writing and mathematics, in Knowing, Learning, and Instruction: Essays in Honor of Robert Glaser (Ref. [71]), p. 453.

[82] C. Bereiter and M. Scardamalia, Cognition and curriculum, in Handbook of Research on Curriculum, edited by P. W. Jackson (MacMillan, New York, 1992), p. 517.

[83] T. Foster, “The development of students' problemsolving skills from instruction emphasizing qualitative problem-solving,' Ph.D. thesis, University of Minnesota, 2000.

[84] J. Heller and F. Reif, Prescribing effective human problem solving processes: Problem description in physics, Cogn. Instr. 1, 177 (1984).

[85] D. W. Johnson, R. T. Johnson, and E. J. Holubec, Cooperation in the Classroom (Interaction Book Company, Edina, MN, 1993).

[86] M.D. Savage and J.S. Williams, Mechanics in Action (Cambridge University Press, London, 1990).

[87] J. Clement, Observed methods for generating analogies in scientific problem solving, Cogn. Sci. 12, 563 (1988).

[88] B. Eylon and U. Ganiel, Macro-micro relationships: The missing link between electrostatics and electrodynamics in students' reasoning, Int. J. Sci. Educ. 12, 79 (1990).

[89] B. Eylon and J. Helfman, Analogical problem-solving processes in physics, in Science Teaching in Israel: Origins, Development and Achievements, edited by A. M. Mayer and P. Tamir (Israel Science Teaching Center, Jerusalem, 1984), p. 259.

[90] M. T. H. Chi, S. Siler, H. Jeong, T. Yamauchi, and R. G. Hausmann, Learning from human tutoring, Cogn. Sci. 25, 471 (2001).

[91] A. Kitchen and J. S. Williams, Implementing and assessing mathematical modelling in the academic 16-19 curriculum, in Teaching and Learning Mathematics in Context, edited by T. Breiteig, I. Huntley, and G. Kaiser-Messmer (Ellis-Horwood, Chichester, England, 1993), p. 127. 
[92] J. Docktor and K. Heller, Assessment of student problem solving processes, AIP Conf. Proc. 1179, 133 (2009).

[93] E. Etkina, A. Van Heuvelen, S. White-Brahmia, D. Brookes, M. Gentile, S. Murthy, D. Rosengrant, and A. Warren, Scientific abilities and their assessment, Phys. Rev. ST Phys. Educ. Res. 2, 020103 (2006).
[94] J. McNiff, P. Lomax, and J. Whitehead, You and Your Action Research Project (Hyde, Bournemouth, England, 1996).

[95] M. G. Fullan and S. Stiegelbauer, The New Meaning of Educational Change (Teachers College Press, New York, 1991), 2nd ed. 